Portland State University

PDXScholar

6-10-1996

\title{
Examining the Relationship between Three Speech Features and Intelligibility Ratings of Black English Preschoolers as Judged by Standard English Listeners
}

Britteny Sue Asher

Portland State University

Follow this and additional works at: https://pdxscholar.library.pdx.edu/open_access_etds

Part of the Speech and Rhetorical Studies Commons

Let us know how access to this document benefits you.

\section{Recommended Citation}

Asher, Britteny Sue, "Examining the Relationship between Three Speech Features and Intelligibility Ratings of Black English Preschoolers as Judged by Standard English Listeners" (1996). Dissertations and Theses. Paper 4917.

https://doi.org/10.15760/etd.6793

This Thesis is brought to you for free and open access. It has been accepted for inclusion in Dissertations and Theses by an authorized administrator of PDXScholar. Please contact us if we can make this document more accessible: pdxscholar@pdx.edu. 


\section{THESIS APPROVAL}

The abstract and thesis of Britteny Sue Asher for the Master of Science in Speech Communication: Speech and Hearing Sciences were presented June 10,1996 , and accepted by the thesis committee and the department.

COMMITTEE APPROVALS:

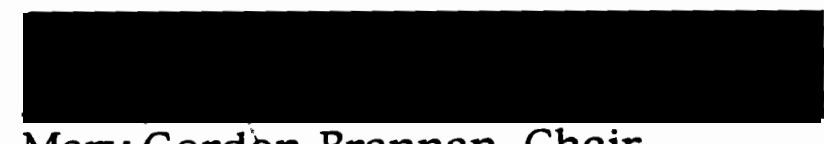

Mary Gordon-Brannan, Chair

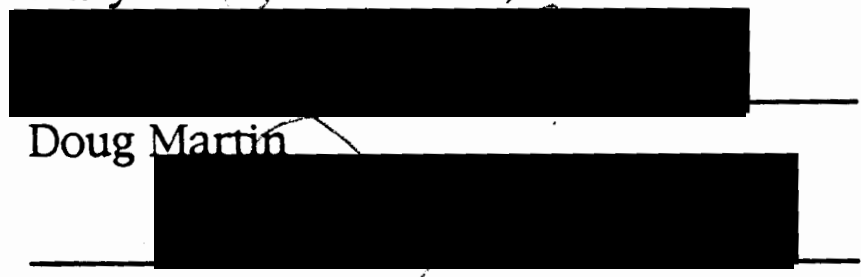

Candice Goucher

Representative of the Office of Graduate Studies

DEPARTMENT APPROVAL:

Rhea Paul, Acting Chair

Department of Speech Communication

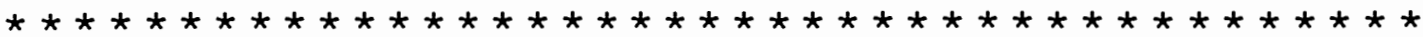

ACCEPTED FOR PORTLAND STATE UNIVERSITY BY THE LIBRARY by on 21 Recquex 1486 


\section{ABSTRACT}

An abstract of the thesis of Britteny Sue Asher for the Master of Science in Speech Communication: Speech and Hearing Sciences presented June 10, 1996.

Title: Examining the Relationship Between Three Speech Features and Intelligibility Ratings of Black English Preschoolers as Judged by Standard English Listeners.

Linguistic diversification within our public schools has demanded professional responsibility from speech-language pathologists (SLPs) serving nonstandard English speaking students. Understanding and recognizing normal cultural linguistic differences is the responsibility of the SLP. This study focused on the relationship of three speech features to intelligibility ratings of 10 preschool aged Black English speakers as assigned by 4 licensed standard English speaking SLPs with varying experience. The SLPs also rated the perceived effect of these speech features (i.e., articulation, speaking rate, and resonance) on intelligibility.

Using the Pearson product-moment correlation, ratings were correlated and found to demonstrate an association between intelligibility ratings and all three speech features assessed. To determine which speech feature affected 
intelligibility the most, a linear association using a stepwise regression was applied to all listeners' ratings. For 3 of the 4 listeners, the strongest association between intelligibility and articulation. Ratings of the 4th listener, the listener with the most experience ( $>3$ years) demonstrated the strong association between intelligibility and resonance. The listener with the least amount of experience tended to assign higher severity ratings to ratings for intelligibility, rate, and resonance than did the other listeners.

Findings from this study demonstrate a need for more studies within the area of Black English as well as further investigative studies to assess listeners' perception of dialectical differences based on the experience within linguistically different or similar communities. Various measures of intelligibility of Black English speakers should also be explored for more accurate assessment tools for this population. Clinical implications focus on the SLP's responsibility to be experienced and knowledgeable of the linguistic community they are serving. 
EXAMINING THE RELATIONSHIP BETWEEN THREE SPEECH FEATURES AND INTELLIGIBILITY RATINGS OF BLACK ENGLISH PRESCHOOLERS AS JUDGED BY STANDARD ENGLISH LISTENERS

\author{
by \\ BRITTENY SUE ASHER
}

A thesis submitted in partial fulfillment of the requirements for the degree of

\author{
MASTER OF SCIENCE \\ in \\ SPEECH COMMUNICATION: \\ SPEECH AND HEARING SCIENCES
}

Portland State University

1996 


\section{ACKNOWLEDGMENTS}

Many holidays, weekends, and evenings were devoted to my finishing this final requirement; with my garden and family suffering the consequences of graduate school long after my course work had been completed.

I want to extend my greatest appreciation to my advisor, Mary Gordon-Brannan. Her guidance and support during many late hours and long weekends, as well as her fax machine, made this possible. Thank you Mary.

I also want to thank my committee members, Doug Martin and Candice Goucher. The summer course Doug offered provided me with the encouragement I needed to get this study off the ground and get it done! Candice pushed me to go beyond my study and to look more closely at the implications of the bigger picture.

As my support team, I want to thank my immediate and extended family, for always understanding my need to put my studies first. Trips to Sunriver, family camping trips, cabin BBQs, and flower expeditions are now top on the list.

As a graduate peer and my research partner, I want to thank Sharon Soliday, for providing me the basis of my study as well as continuous laughter throughout the grueling audio tape editing process. As my best girl friend I want to thank her for 
understanding and supporting my need to work on my thesis rather than play, shop, garden, or just sit and talk, now also on the priority list!

And finally to my top priority, my best friend and husband, David. I thank him for always putting my studies first, even when I didn't. Without his gentle reminders and stern refusal of my often creative avoidance tactics this thesis would not have been completed. His support kept our house affairs managed, the garden flourishing, and my mind at ease. Thank you and I love you! Now let's play!! 


\section{LIST OF TABLES}

TABLE

PAGE

1 Range and Mean of Intelligibility Ratings Among all Four Listeners . . . . . . 32

2 Range and Mean of Articulation Ratings Among all Four Listeners . • . . . . 33

3 Range and Mean of Rate Ratings Among all Four Iisteners $\quad$. . . . . . . . . 34

4 Range and Mean of Resonance Ratings Among all Four Listeners . . . . . . . 35 


\section{LIST OF FIGURES}

FIGURE

PAGE

1 Three Speech Samples Rated Twice by Rater A 27

2 Three Speech Samples Rated Twice by Rater B 28

3 Three Speech Samples Rated Twice by Rater C 29

4 Three Speech Samples Rated Twice by Rater D 30

5 Intelligibility Ratings of Speech Samples Assigned by 4 Raters . . . . . . . . . . 39

6 Assigned Ratings for Rate for each Speech Samples . . . . . . . . . . 42

7 Assigned Ratings for Resonance for each Speech Samples . ... . . . . . . . . 43

8 Assigned Ratings for Articulation for each Speech Samples . . . . . . . . . 44

9 Relationship of Intelligibility and Assessed Speech Features for Rater C . . . . . . . . 46

10 Relationship of Intelligibility and Assessed Speech Features for Rater D . . . . . . . . 48 
TABLE OF CONTENTS

PAGE

ACKNOWLEDGMENTS

ii

LIST OF TABLES . . . . . . . . . . . . . . iv

LIST OF FIGURES . . . . . . . . . . . . $\mathrm{v}$

CHAPTER

I INTRODUCTION AND STATEMENT OF PURPOSE

Introduction . . . . . . . . . 1

Statement of Purpose . . . . . . 4

Definition of Terms . . . . . . 5

II REVIEW OF THE LITERATURE

History of Bilingual Education . . . 7

Bilingual Education in General . 7

Legislation and Bilingual Education 8

Intelligibility . . . . . . . . . 11

Speech Intelligibility Defined $\quad$. 11

Factors Affecting Intelligibility . 12

Measuring Intelligibility . . . 14

Black English Speech Development 19

Normal Development . . . . 19

Black Dialect . . . . . . . 20 
II I METHODS

$$
\begin{aligned}
& \text { Subjects . . . . . . . . . } 21 \\
& \text { Materials . . . . . . . . } 21 \\
& \text { Procedures . . . . . . . . . } 22 \\
& \text { Reliability . . . . . . } 24
\end{aligned}
$$

IV RESULTS AND DISCUSSION

$$
\begin{aligned}
& \text { Results . . . . . . . . . } 26 \\
& \text { Reliability . . . . . . } 26 \\
& \text { Intrajudge Reliability . } 26 \\
& \text { Interjudge Reliability . } 31 \\
& \text { Research Question } 1 \text {. . . . } 36 \\
& \text { Research Question } 2 \text {. . . . } 37 \\
& \text { Discussion . . . . . . . . } 38 \\
& \text { V SUMMARY AND IMPIICATIONS }
\end{aligned}
$$

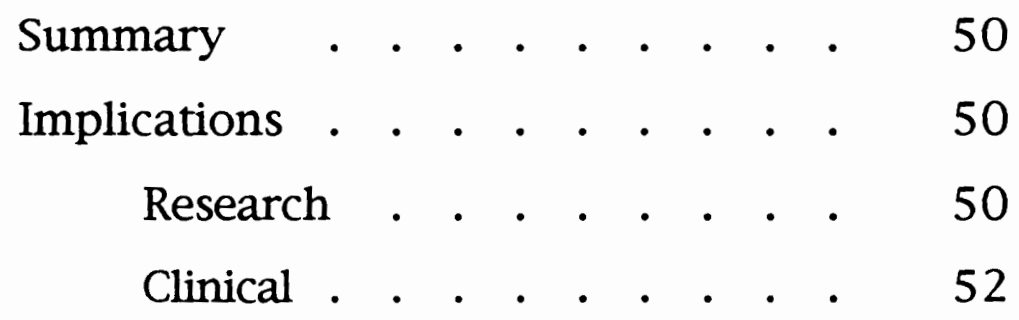$$
\text { REFERENCES . } \quad \text { • } \quad . \quad \text {. . . . . . } 54
$$ 
viii

PAGE

\section{APPENDIXES}

A Explanation of Black English Rules . . . 62

B Consent Form . . . . . . . 65

C Rating Scale for Intelligibility . . . . . 67

D Assessing Intelligibility Factors . . . . 68

E Description of Factors Influencing Intelligibility

F Rater's Instructions . . . . . . . . 73

G Competencies for Speech-Language

Pathologists Working with Non-standard English Speakers . . . . . . . 75

H Alternative Strategies for Use of

Professional Personnel . . . . . 76 


\section{CHAPTER I}

\section{INTRODUCTION AND STATEMENT OF PURPOSE}

\section{Introduction}

Recent acknowledgment of the occurrence of cultural and linguistic differences within the public school setting has resulted in a new emphasis on the identification and assessment of distinctive nonstandard English speaking language types within this diverse setting. Acknowledgment of the distinctive language types used by different populations within school systems must be followed by the acceptance of diverse language use and style (Hamayan \& Damico, 1991). Unfortunately, for both communication partners, the acceptance of language differences in speakers (e.g., dialectal differences) often affects the intelligibility of a speaker. In other words, when a dialectal difference is not accepted by listeners, the listeners' perception of how well they are able to understand the speaker will be decreased. Better understanding of the speaker's style and manner of communication will increase the chances of a successful communication exchange. In terms of speech and language service, awareness and understanding of language differences will assist in the service provider's ability to determine what services should or should not be provided for the nonstandard English student, including the Black English speaker. 
While students may be proficient in their native language, they may be perceived as different, or even disabled, by monolingual, standard English speakers (Rueda, 1987). The behavioral characteristics that most frequently separates the nonstandard English student from the mainstream is in the area of verbal communication. "If viewed from a monolingual English perspective, these students may be misidentified as exhibiting both speech and language problems" (Hamayan \& Damico, 1991, p. 31). When using standard English, nonstandard English speaking students may be misdiagnosed as language disordered due to the normal processes of second language acquisition (e.g., rule fossilization, cultural interactional differences, and first language interference). Specific linguistic features that may affect intelligibility of Black English include content (e.g., the level of difficulty of the message), style (e.g., speed and hesitations), and linguistic form (e.g., how close or deviant the form of the message is from the target language) (Hamayan \& Damico, 1991). These differences may be initially identified by the standard English speaking listener as a speech or language disorder based solely on that listener's inability to understand the nonstandard English speaker.

Hamayan and Damico (1991) suggested students of culturally, ethnically, and linguistically diverse backgrounds are subjected to various forms of bias, including misdiagnosis of special education needs either in the form of overrepresentation 
or underrepresentation. It has been well documented that certain categories of special education, including service for speech and language skills, are overrepresented by as much as $60 \%$ to $80 \%$ in individuals who are from culturally and linguistically different populations ( Finn, 1982; Mercer, 1983; Ortiz \& Maldonado-Colon, 1986; Ortiz \& Wilkinson, 1987) and/or lower socioeconomic status (Dunn, 1968).

When determining eligibility for speech and language services, it is the task of the speech-language pathologist (SLP) to determine the reason for the referral for a communication assessment. A common form of referral within the school setting is through teachers who experience difficulty understanding students within the classroom. Following a staff referral, a SLP may observe the student within the classroom prior to beginning the paperwork for a formal assessment. It is in this initial and informal observation when a student may be initially identified as needing services. During this observation, a SLP must be able to differentiate difficulties resulting from the normal secondlanguage-learning process or experiential and cultural differences from intrinsic language-learning impairments (Damico, 1991). The ability to determine children's language proficiency and intelligibility in their native language must be addressed through measuring their mastery of their native language in terms of the sounds, the grammatical rules, and the vocabulary of that language. Proficient use of a language 
involves mastery of the discourse rules that govern acceptable communication among members of the society where the language is commonly used (Macnamara, 1967).

Determining the speech and language needs of students is the responsibility of SLPS, and with this responsibility falls the ethical obligation of continued and constant familiarity of diverse language types used within their working population. It is this familiarity and knowledge that will assist SLPs in using their best professional judgment when separating those nonstandard English students who are referred for service based on their true speech and language needs from the linguistic and cultural differences which make up our diverse public school populations.

\section{Statement of Purpose}

Intelligibility of expressive speech is affected by a multitude of compounded components. For the purpose of this study, three speech features that may affect the subjective intelligibility rating of a standard English speaking SLP of a Black English speaker will be explored. The questions this study will seek to answer are: (a) do the speech features of articulation, rate, and resonance affect a standard English speaking SLP's assigned intelligibility ratings of BE speaking preschoolers; and (b) if so, which of these speech features affect the assigned intelligibility rating the most. 
For the purposes of this study, only three speech features are being isolated to determine their specific role in intelligibility. These features were selected on the basis of data from a pilot study conducted by the examiner. It is vital that further studies explore the effects of other features, both linguistic and nonlinguistic, on intelligibility to insure that legitimate services are provided to nonstandard English speaking students within the diverse school populations.

\section{Definition of Terms}

For the purpose of this study, the following operational definitions were utilized.

Black English. “. . . the entire range of linguistic forms used by black Americans" (Labov, 1980, p. 273). It is systematic and rule governed in its syntax (grammar), phonology (sound system), and semantics (system of meaning).

Copula. Form of the verb to be as a main verb. Signifies a relationship between the subject and a predicated adjective or another noun (Owens, 1988).

Dialect. Clusters of linguistic features associated with geographic regions (Patterson, 1994) or social/cultural influence (Edwards, 1980).

Intelligibility. How well a speaker is understood by a listener, without the presence of visual cues (Buekelman \& Yorkston, 1979; Connolly, 1986; Metz, Schiavetti, \& Sitler, 1980). 
Linguistic. The components of language, including form (syntax, morphology, and phonology), content (meaning and semantics), and use or pragmatics (Bloom \& Lahey, 1978).

Nonlinguistic. Features that include the relationship with the speaker, the physical characteristics of the speaker that may be distracting; factors within the environment that may be distracting; and the psychological state of the listener and the native language of the speaker and the listener (Fayer \& Krasinski, 1987).

Standard American English. The language dialect achieving social prestige in the United States (Taylor, 1987). 


\section{CHAPTER II}

REVIEW OF THE LITERATURE

History of Bilingual Education

\section{Bilingual Education in General}

Intelligibility is a primary component that affects the outcome of a minority speaker's message. This component becomes critical when looking at the total number of culturally and linguistically diverse students within the public school system and assessing their predicted success within a standard English-based classroom. Although estimates of the number of nonstandard English students in the United States school system vary, even conservative estimates reveal significant numbers. A 1980 Census of Population revealed that in 29 of the 50 states, at least $10 \%$ of the school-aged population came from linguistically diverse families. At the time of the census, Oregon had an estimated distribution of $10.1 \%$. (Office of Civil Rights, 1980).

Difficulties in the assessment and placement of nonstandard English students in special education has been reported by local authorities around the United States (Hamayan \& Damico, 1991). Reports indicate nonstandard English students have been misdiagnosed or underdiagnosed, with examples such as the overrepresentation of bilingual students in classes for the 
educable mentally handicapped, but underrepresentation in classes for learning disabilities (Finn, 1982).

Determining eligibility for speech and/or language services requires the application of normative data to ascertain if individuals are developing at or below the level of their peers (e.g., age, race, sex, geographical region, and socioeconomic level). Although a multitude of speech and language assessments exist, the majority of these assessments are normed on standard English speakers; therefore theses assessment tools are often inappropriate for individuals from other linguistic backgrounds. One protocol, the Assessment of Phonological Processes Revised (APP-R) (Hodson, 1986) a tool for analyzing the use of phonological processes has been found not to be negatively influenced by the Black English (dialect), although it is normed on standard English speakers (Soliday, 1993). More studies like the Soliday study would allow SLPs needed information regarding the bias of protocols available, until then, the availability of information and appropriate assessments for the nonstandard English speaker are limited.

\section{Legislation and Bilingual Education}

Two statutory acts served to prohibit discrimination on the basis of race, color, sex, national origin, or language. The first, Title VI of the Civil Rights Act (1964), did not originally contain 
a prohibition against discrimination on the basis of language. The interpretation of protecting linguistically diverse students from inappropriate program placement was added in an HEW policy guideline titled "Identification of Discrimination" in 1970. The second statutory prohibition is an inserted section in the Equal Educational Opportunities Act of 1974, Section 1703(f), prohibiting denial of educational opportunities due to the failure to overcome language barriers that impede instructional participation.

In the landmark case of Lau v. Nichols (1974), as cited in Hamayan \& Damico (1991), the Supreme Court ruled that the San Francisco school district had violated these two Acts because the school district was not providing special English classes with bilingual teachers to Chinese American students, therefore denying them an education. From this suit, rose district guidelines to meet the needs of nonstandard English speaking students; these guidelines were eventually developed as the Lau Remedies. The Lau Remedies focused on identification of linguistically diverse students, assessment of their language proficiency and academic performance, and their placement in appropriate educational programs. This suit in conjunction with subsequent suits established what is considered to be appropriate education for nonstandard English speaking students in the United States from a judicial perspective (Hamayan \& Damico, 1991). 
In another important case, the legitimacy of Black English was established. This 1979 decision, often referred to as the Ann Arbor decision, determined that teachers of Martin Luther King Junior Elementary School of Ann Arbor, Michigan were rejecting the home language of the minority students, whether consciously or unconsciously. The parents of the Black English speaking children asked the courts to make a ruling that would make teachers more sensitive to the "home language" when teaching standard English to black children. The judge ruled that the school board of Ann Arbor had to develop a plan to help the teachers of the King School identify speakers of Black English within their classroom and learn to use the knowledge of their Black English background as they teach them to read standard English.

These two cases, and many more like them, served to establish the acknowledgment of linguistically diverse language systems. With a new emphasis to teach students of diverse cultural, ethic, and linguistic backgrounds, service providers had to assess and provide services to students in their native language. With this ruling, eligibility could no longer be established for speech and language based solely on the students' use and intelligibility of their now "second language" English. These landmark cases have changed the way an SLP must "listen" to speakers. Whereas before, intelligibility was based on a speaker's ability to be intelligible in standard English 
to the standard English listener, these new laws now challenge the standard English listener to understand the speaker in the speaker's native language.

\section{Intelligibility}

One method of speech and language referral often used by a SLP within a school setting is teacher referral. It is highly possible a student would be referred to a SLP based on a listener's inability to understand much of a student's speech. Due to the fact that intelligibility is listener based, the SLP has the responsibility to determine if intelligibility is a primary factor for the referral. If it is determined that intelligibility is a factor, the SLP must further investigate the linguistic differences that may contribute to the communication breakdown. It is important that SLPs clearly distinguish the speaker's possible second-language use differences that contribute to lack of intelligibility from real speech and/or language disorders or delays occurring in the student's native language.

Speech Intelligibility Defined

Intelligibility has been defined as " listener based, that is, how well a speaker is understood by the listener, without the presence of visual cues" (Buekelman \& Yorkston, 1979; Connolly, 1986; Metz et al., 1980). Speech intelligibility is a subjective judgment made by the listener regarding the degree to which a 
person's speech is understood by the listener (Fayer \& Krasinski, 1987; Nicolosi, Harryman, \& Kresheck, 1989; Weiss, Gordon, \& Lillywhite, 1987). Many clinicians and researchers consider intelligibility to be the single-most practical measurement of oral communication competence, often using intelligibility as an indicator of overall speech adequacy (Beukelman \& Yorkston, 1979; Connolly, 1986; Yorkston, Beukelman, \& Bell, 1988).

Factors Affecting Intelligibility

How well an individual is understood by listeners often affects the listeners' attention, mood, and returning message. The clarity or intelligibility of the message may be affected by many different factors. Suprasegmental factors that may affect intelligibility include prosodic features (e.g., pitch inflection, open and closed juncture, pause, speaking rate, and stress), voice characteristics (voice quality, intensity level, and resonation), and fluency. Contextual/linguistic features partially affecting intelligibility include articulation, phonology, syntax, mean length of utterance, morphology, morphophonemics, and semantics. Pragmatics, the listener's relationship with the speaker, the speaker's topic, physical characteristics of the speaker that are distracting, environmental distractions, the psychological state of the listener, and the native languages of the speaker and the listener (including dialectal differences, and the nature of the transmission medium) may also affect 
intelligibility (Eisenstein \& Verdi, 1985; Gordon-Brannan, 1994;

Nicolosi et al.; Olshtain, Shohamy, Kemp, \& Chatow, 1990).

Linguistic disadvantage (i.e., linguistic differences) of students and their environment is often said to be a major cause for lack of success of children in school (Olshtain et al., 1990).

Although research is still limited in the area of nonstandard English and intelligibility, many authors have studied the effects of multiple influences on intelligibility of standard English speakers. Numerous articulation variables affect intelligibility within a single utterance, including number of sounds in error per word, the frequency of occurrence of errors, and the variability of errors. These variables make identifying and measuring intelligibility a difficult task (Shriberg \& Kwiatkowski, 1982; Weiss, 1982).

The literature available on the topic of intelligibility is almost entirely based on data from English-speaking subjects. An exception is a study conducted by Yavas and Lamprecht (1988). These authors identified the cluster reduction and stopping processes as contributing to unintelligibility of four 7to 9-year-old Portuguese-speaking students who were phonologically disordered. Cluster reduction and stopping processes are typical of Portuguese speakers.

Eisenstein and Verdi (1985) conducted an investigation of the intelligibility of three English dialects: standard English, New Yorkese, and Black English. The intelligibility of the subjects was 
rated based on the comprehension of six tape-recorded contextualized monologues. The results of this study indicated comprehension was significantly affected by dialect and that Black English was the least intelligible of the three dialects investigated.

In an earlier study, Eisenstein (1982) found the English listener's ability to recognize dialectical differences occurs early in the learning process; however, the listener's ability to identify and categorize specific varieties of dialects develops more slowly. Eisenstein's study demonstrated the increasing need to acknowledge and understand the differences among different dialectical speakers, so that as service providers, speechlanguage pathologists can best serve all populations without bias based on language differences.

\section{Measuring Intelligibility}

Researchers have made use of many elicited and spontaneous forms of language sampling including word lists, paragraph readings, and continuous speech samples to measure intelligibility of a speaker (Buekelman \& Yorkston, 1979; Metz et al., 1980; Monsen, 1981; Schiavetti, 1984, 1992; Weiss, 1982; Yorkston \& Beukelman, 1978).

Review of the literature reveals three standard approaches for measuring intelligibility. The open set word identification procedure is an approach in which the percentage of words 
understood in a conversation, reading sample, or single words is calculated (Kent, 1992; Weiss, 1992). For this approach, the examiner orthographically transcribes the speech sample and determines the percentage of words correctly identified (Gordon-Brannan, 1994).

A second approach, referred to as the closed-set or multiple-choice method, uses word lists to yield intelligibility ratings (Monsen, 1981; Morris, Wilcox, \& Schooling, 1995). Words used for closed-set intelligibility measurements are often comprised of one-and two-syllable words that are presented by the examiner and then repeated by the client (Morris et al., $1995)$ or from word lists that the client reads (Monsen, 1981). Fudala and Reynolds (1986) developed a single word articulation test, the Arizona Articulation Proficiency Scale (AAPS) that assesses the production of consonants in the initial and final positions. Based on an assigned numerical value of each consonant as outlined by the authors, the child's performance can be converted to an estimation of intelligibility.

In their study, Shriberg and Kwiatkowski (1982) presented a detailed systematic procedure for rating the severity of a speech impairment by quantifying the number of misarticulations. Other studies have shown this severity measurement to correlate highly with intelligibility measures (Weiss, 1982). Using a different approach, Ingram (1981) tracked the number of different lexical items associated with the 
same phonological forms, homophones. Ingram found the presence of homophones, words pronounced alike, such as find, found, and fond, to be a key factor of intelligibility, concluding that children who use excessive homonymy are likely to be less intelligible.

It is important to remember that speech samples analyzed at the sound-by-sound level may crudely represent an individual's true intelligibility rating at the conversational level since this type of assessment consists of elicitation of nonrelated words, usually presented by the examiner, who knows the desired target sound being elicited. A decrease in intelligibility may become more apparent when a continuous speech sample is obtained due to the speech sample's increased naturalness with the speaker's primary focus on content rather than articulation, rate, or form (Yavas \& Lamprecht, 1988).

An alternative to the orthographic transcription of speech samples involves a listener rating a spontaneous speech sample. In this approach the listener uses rating scales to judge the speaker's intelligibility. To assist with determining the level of intelligibility, researchers have devised intelligibility rating scales, in which a number is assigned to the listener-determined level of severity of a speaker's intelligibility.

Two types of scaling techniques have been used for rating the intelligibility of speech, that is, direct magnitude scaling and equal-interval. With direct magnitude scaling, listeners judge a 
speech sample "with a number that is proportional to the perceived ratios of speech intelligibility among the speech sample" (Schiavetti, 1992, p. 20). Using equal-interval scaling, on the other hand, the listener assigns the entire utterance to a numerical point along a scale, with coinciding descriptors at various points. Commonly, equal-interval scales have five, seven, or nine points (Gordon-Brannan, 1993).

Scaling procedures are often used for two reasons: (a) it is considered the most direct assessment for a particular dimension of communication, and (b) it is a relatively simple means of measuring intelligibility in a quantitative manner (Schiavetti, 1984). Young (1969) stated, ".... a measure of a speech disorder is primarily a perceptual event, and the observer's response necessarily represents the 'final' validation for any measurements" (p. 135). Thus Young pointed out the need for the listener to analyze an entire utterance, as a whole, rather than looking at individual parts of the utterance when assessing intelligibility as well as other speech and language delays or disorders.

As mentioned above, the second advantage to scaling is the relative simplicity in the scaling procedure. It is often used as an appropriate alternative to a more expensive, time consuming, and cumbersome measurement procedures (Schiavetti, 1984). Others note that use of scaling procedures requires fewer listeners than word identification tests (Metz et al., 1980), 
maintains interest of the raters, allows the opportunity to use naive raters with a minimum of training, and is useful with a large number of stimuli (Guilford, 1954). Review of the literature revealed both direct magnitude and equal-interval scaling are used, by themselves or in combination with one another to identify intelligibility of speakers who have dysarthria, disordered phonology, hearing impairments, and who are alaryngeal speakers.

Yorkston and Beukelman (1978) compared all three different measures of intelligibility of dysarthric speakers: a) closed-set or multiple choice, b) rating scale, and c) transcription. They found these measures yield comparable results when compared with one another. In his research, Weiss (1982) identified 20 linguistic features which may affect the intelligibility ratings of a speaker. Unfortunately, further studies on the impact of these features or more specific information regarding these 20 linguistic features and particular speakers have not been undertaken. Furthermore, studies looking at the aspects of language development beyond the scope of specific dialectal differences (i.e., verb phrases and copula and auxiliary deletion), is critically incomplete (Hamayan \& Damico, 1991; Vaughn-Cooke, 1983) leaving the service providers without a reference or a guideline to provide accurate service to these linguistically different populations. 
Black English Speech Development

\section{Normal Development}

During the past three decades, SLPs have made considerable gains in their knowledge of child language development among the mainstream English speaker. The study of language development among the Black English speaking population, however, has been much slower. Early pioneers in this effort include Henrie (1969), Kovac (1980), Reverton (1978), Steffenson (1974), and Strokes (1976). While the work of these authors contributed to bridging the gap of knowledge existing on language development of nonmainstreamed Black English speaking children, the studies had several limitations. The first limitation was that only a small subset of language structures were described for children, specifically verb phrases used by 5year-old Black English speakers (Henrie, 1969); negative structures used by 3-to 5-year-olds (Strokes, 1979); absence of copulas in children between the ages of 4 and 6 years (Kovac, 1980); and finally, the occurrence of plurals, possessives, past tense, and third-person singular morphological markers of 3-and 6-year-olds (Reverton, 1978). Further limitations of these initial studies included their focus on grammatical form without regard for the content. Acquisition of phonological rules and the developmental acquisition of Black English has not been fully explored. The acquisition of nonmainstreamed dialects, 
including those acquired by working-class black children, remains practically unexplored (Stockman, 1982).

Lack of comprehensive knowledge beyond limited descriptions of Black English dialect and the fact that norms for assessing language capabilities of the Black English speaking population are still not adequate at this time, make it virtually impossible for SLPs to identify those Black English students who exhibit language delays and disabilities (Mercer, 1983).

\section{Black Dialect}

Dialect refers to clusters of linguistic features associated with geographic regions (Patterson, 1994). For example, some African American speakers use a variety of English, termed Black English Vernacular or Black English. Wolfram and Fasold (1974) provided a complete discussion of both the phonological and grammatical features of Black English dialect. For the purposes of this study, a brief overview of the grammatical and phonological rules of Black English presented by Cole (1983) is included in Appendix A. 


\section{CHAPTER III}

\section{METHODS}

\section{Subjects}

Four licensed SLPs from the Portland, Oregon metropolitan area were the subjects of this study. All subjects were female, Caucasian, standard English speakers with a range of experience with Black English speakers from less than 6 months to more than 3 years. One subject had less than 6 months experience, 2 had between 6 months and 2 years experience, and 1 had more than 3 years experience. In order to participate in this study, the subjects signed informed consent forms (Appendix B).

\section{Materials}

Audiotaped speech samples of 10 black, lower socioeconomic preschoolers from the Soliday (1993) study were used to determine speech intelligibility. The mean age for the group was 4:0 (years: months), with a range of $3: 6$ to $4: 6$. At that time, subjects were recruited from preschool programs in the Portland, Oregon metropolitan area. All subjects from that study passed a pure-tone hearing screening at $25 \mathrm{~dB}$ for the frequencies of $500,1000,2000$, and $4000 \mathrm{~Hz}$, as well as an evaluation to determine typically developing cognition, articulation, and receptive language skills as reported by teachers and SLPs. All subjects demonstrated age appropriate 
outcomes on the Assessment of Phonological Processes-Revised (Hodson, 1988) in conjunction with the Computer Analysis of Phonological Deviations (Hodson, 1986) as assessed by a speechlanguage pathology master's level student in the original study.

A portable Realistic tape player was used to present the recorded speech samples to the SLPs. A Likert-type rating scale (Appendix C) developed in a previous study (Gordon-Brannan, 1993) was used by the SLPs to rate overall intelligibility of the continuous speech samples. Using the 7-point scale, 1 was defined as essentially unintelligible, $\underline{4}$ as sometimes intelligible, and $\underline{Z}$ as essentially intelligible. The SLPs further assessed the samples, rating the effect of articulation, rate, and resonance on intelligibility using a 5-point rating scale for speech features adapted from Casteel (1971)(Appendix D). Using the 5-point scale, $\underline{5}$ was defined as within normal limits, $\underline{4}$ as does not interfere with intelligibility, $\underline{3}$ as slightly interferes with intelligibility, $\underline{2}$ as moderately interferes with intelligibility, and 1 as severely interferes with intelligibility.

\section{Procedures}

In order to allow the SLPs a feasible listening task, a pilot study was undertaken. The principal investigator for this study served as the sole listener for the pilot study. Using the audiotaped samples from the Soliday (1993) study, three 
randomly chosen speech samples were used to examine all 20 features affecting intelligibility as identified by Weiss (1982) (Appendix E). From this pilot study, three speech features were identified as primary features affecting overall listener intelligibility in each of the three speech samples: (a) articulation, (b) rate, and (c) resonance.

Following the conclusion of the pilot study, research was initiated on the 10 remaining audiotaped samples from the Soliday (1993) study. Unknown to the listeners, 3 of the samples were placed at the end of the tape for the listeners to rate a second time. These were used later for intrajudge reliability measures of the ratings. The instructions for rating were provided to the listeners both orally and in written form (Appendix F). All four SLPs listened to each audiotaped speech sample and provided subjective overall intelligibility ratings using a 7-point Likert scale.

Following the overall intelligibility rating, the SLPs again listened to the taped samples. Without their intelligibility ratings available for review, using the 5-point scale, the SLPs assigned a numerical rating to each of the three speech features selected for investigation relative to their perceived contribution to the speaker's unintelligibility (Appendix D). 
$\underline{\text { Reliability }}$

Intrajudge reliability for the ratings were examined through discrepancy scores between the two ratings for each of the three speech samples presented twice. Discrepancy scores were determined for intelligibility ratings, articulation ratings, rate ratings, and resonance ratings assigned by each listener to each of the three taped samples heard and rated twice by the SLPs.

Interjudge reliability was established through the comparisons of the listeners' assigned ratings of the 10 speech samples within each rated area: intelligibility, articulation, rate, and resonance. The listeners' range in points on the 7-point intelligibility rating scale and 5-point speech features rating scales, as well as the mean rating for each of the assessed areas per speech sample was then calculated.

\section{Measurement and Data Analysis}

The first research question regarding whether the three speech features assessed (articulation, rate, and resonance) affect assigned intelligibility ratings was examined by correlating the ratings of each speech feature with the intelligibility rating using the Pearson product-moment correlation (Pearson $\mathrm{r}$ ). The second research question that addressed the question, if these speech features do affect intelligibility ratings, which of the features affect the ratings the 
most was investigated by determining the linear association of intelligibility and these features as determined by a stepwise regression analysis. 
Chapter IV

RESULTS AND DISCUSSION

Results

This study investigated the possible affects the speech features of articulation, rate, and resonance have on the assigned intelligibility ratings of Black English speaking preschoolers by Standard English speaking Speech-Language Pathologists. Reliability

Before addressing the research questions, inter- and intrajudge reliability was examined.

Intrajudge reliability. Intrajudge reliability was assessed using a descriptive model to compare the data for the listeners' ratings of three speech samples rated twice. Given three identical speech samples, with each being rated in four areas (i.e., speech intelligibility, articulation, rate, and resonance), visual inspection of the data shows that listeners rated the majority of the speech samples similarly, with only minimal differences.

Figure 1 displays the rating discrepancies across the speech samples for Rater A. Rater A assigned the same rating to 6 of the 12 rated areas for the three speech samples. The mean rating differences for Rater A were .33 for intelligibility and rate 


\begin{tabular}{|c|c|c|c|c|c|}
\hline \multirow{4}{*}{$\begin{array}{l}\text { Speaker } 1 \\
\text { Speech } \\
\text { Samples }\end{array}$} & & Intelligibility & Articulation & Rate & Resonance \\
\hline & 1 & 6 & 5 & 5 & 4 \\
\hline & 11 & 6 & 4 & 5 & 4 \\
\hline & Difference & 0 & 1 & 0 & 0 \\
\hline
\end{tabular}

Speaker 2

Speech

Samples

\begin{tabular}{|c|c|c|c|c|}
\hline 2 & 7 & 4 & 5 & 4 \\
\hline 12 & 7 & 5 & 5 & 5 \\
\hline Difference & 0 & 1 & 0 & 1 \\
\hline
\end{tabular}

Speaker 3

Speech

Samples

\begin{tabular}{|c|c|c|c|c|}
\hline 3 & 5 & 3 & 5 & 5 \\
\hline 13 & 6 & 3 & 6 & 6 \\
\hline Difference & 1 & 0 & 1 & 1 \\
\hline
\end{tabular}

Figure 1. Three speech samples rated twice by Rater A .

Note: Intelligibility ratings may range from $7=$ Essentially Intelligible to $1=$ Essentially Unintelligible. Articulation, rate and resonance ratings may range from $5=$ Within normal limits to $1=\underline{\text { Severely interferes with intelligibility. }}$

and .67 for the perceived effects of articulation and resonance.

Visual inspection of the intrarater data for Rater B showed high reliability. Rater B assigned the same rating to all areas across the three speech samples, with only one exception (see Figure 2). The mean difference for the intelligibility rating was .33 , and 0 for the perceived effects of the three factors investigated in this study. Rater $C$ assigned the same rating for 8 of the 12 rating 


\begin{tabular}{|c|c|c|c|c|c|}
\hline \multirow{3}{*}{$\begin{array}{l}\text { Speaker } 1 \\
\text { Speech } \\
\text { Samples }\end{array}$} & & Intelligibility & Articulation & Rate & Resonance \\
\hline & 1 & 6 & 5 & 5 & 3 \\
\hline & 11 & 7 & 5 & 5 & 3 \\
\hline & Difference & 1 & 0 & 0 & 0 \\
\hline
\end{tabular}

\begin{tabular}{|c|c|c|c|c|c|}
\hline \multirow{3}{*}{$\begin{array}{l}\text { Speaker } 2 \\
\text { Speech } \\
\text { Samples }\end{array}$} & 2 & 7 & 5 & 5 & 5 \\
\hline & 12 & 7 & 5 & 5 & 5 \\
\hline & Difference & 0 & 0 & 0 & 0 \\
\hline
\end{tabular}

\begin{tabular}{l|c|c|c|c|c|} 
Speaker 3 & 3 & 7 & 5 & 5 & 5 \\
\cline { 2 - 6 } $\begin{array}{l}\text { Speech } \\
\text { Samples }\end{array}$ & 13 & 7 & 5 & 5 & 5 \\
\cline { 2 - 6 } & Difference & 0 & 0 & 0 & 0 \\
\cline { 2 - 6 } & & &
\end{tabular}

Figure 2. Three speech samples rated twice by Rater B.

Note: Intelligibility ratings may range from $7=$ Essentially Intelligible to $1=$ Essentially Unintelligible. Articulation, rate and resonance ratings may range from $5=$ Within normal limits to $1=\underline{\text { Severely interferes with intelligibility. }}$

areas across the three speech samples (Figure 3 ). The mean rating difference for Rater C was .33 for intelligibility, articulation, and resonance and 1.0 for the perceived effect of rate. Rater $\mathrm{D}$ assigned like ratings in 10 out of 12 rating areas for the three speech sample (Figure 4). Rater D was the only listener to demonstrate more than a 1 point difference between like speech sample ratings, which occurred for one speaker on resonance. The mean rating difference for Rater $D$ were 0 for 


\begin{tabular}{|c|c|c|c|c|c|}
\hline \multirow{4}{*}{$\begin{array}{l}\text { Speaker } 1 \\
\text { Speech } \\
\text { Samples }\end{array}$} & & Intelligibility & Articulation & Rate & Resonance \\
\hline & 1 & 6 & 3 & 3 & 3 \\
\hline & 11 & 6 & 3 & 3 & 3 \\
\hline & Difference & 0 & 0 & 0 & 0 \\
\hline
\end{tabular}

Speaker 2

Speech

Samples

\begin{tabular}{|c|c|c|c|c|}
\hline 2 & 7 & 5 & 4 & 5 \\
\hline 12 & 6 & 5 & 5 & 5 \\
\hline Difference & 1 & 0 & 1 & 0 \\
\hline
\end{tabular}

Speaker 3

Speech

Samples

\begin{tabular}{|c|c|c|c|c|}
\hline 3 & 5 & 4 & 3 & 4 \\
\hline 13 & 5 & 3 & 4 & 3 \\
\hline Difference & 0 & 1 & 2 & 1 \\
\hline
\end{tabular}

Figure 3. Three speech samples rated twice by Rater C.

Note: Intelligibility ratings may range from $7=$ Essentially Intelligible to $1=$ Essentially Unintelligible. Articulation, rate and resonance ratings may range from $5=$ Within normal limits to $1=\underline{\text { Severely interferes with intelligibility. }}$ 


\begin{tabular}{|c|c|c|c|c|c|}
\hline \multirow{4}{*}{$\begin{array}{l}\text { Speaker } 1 \\
\text { Speech } \\
\text { Samples }\end{array}$} & & Intelligibility & Articulation & Rate & Resonance \\
\hline & 1 & 6 & 5 & 5 & 3 \\
\hline & 11 & 6 & 5 & 5 & 4 \\
\hline & Difference & $\overline{0}$ & 0 & 0 & 1 \\
\hline
\end{tabular}

\begin{tabular}{l|c|c|c|c|c|} 
Speaker 2 & 7 & 5 & 5 & 5 \\
\cline { 2 - 6 } $\begin{array}{l}\text { Speech } \\
\text { Samples }\end{array}$ & 12 & 7 & 5 & 5 & 5 \\
\cline { 2 - 6 } & Difference & 0 & 0 & 0 & 0 \\
\cline { 2 - 6 } & & &
\end{tabular}

\begin{tabular}{|c|c|c|c|c|c|}
\hline \multirow{3}{*}{$\begin{array}{l}\text { Speaker } 3 \\
\text { Speech } \\
\text { Samples }\end{array}$} & 3 & 5 & 3 & 5 & 3 \\
\hline & 13 & 5 & 3 & 5 & 5 \\
\hline & Difference & 0 & 0 & 0 & 2 \\
\hline
\end{tabular}

Figure 4. Three speech samples rated twice by Rater D.

Note: Intelligibility ratings may range from $7=$ Essentially Intelligible to $1=$ Essentially Unintelligible. Articulation, rate and resonance ratings may range from $5=$ Within normal limits to $1=\underline{\text { Severely interferes with intelligibility. }}$

intelligibility, articulation, and rate, and 1.0 for resonance.

While listener's intelligibility ratings were not available for them to review while rating the contributing features, Rater $D$ was noted for scoring 2 speech samples (\# 6 and 9) as 7 (essentially intelligible) while scoring articulation on one sample and articulation and rate on the other sample as 3 (slightly interferes with intelligibility). These ratings may suggest that this listener did not apply the same measurement (i.e., 
qualitative versus quantitative) to their subjective ratings of intelligibility versus speech feature ratings.

Although variance is noted between ratings of three speech samples rated twice by each listener, ratings were within one point of each other, with one exception. Given the overall consistency in the ratings of each area assessed, intrajudge ratings are considered to be reliable.

Interjudge Reliability. Interjudge reliability was established through correlations among each listener's ratings for the 10 speech samples. When comparing intelligibility among the listeners, 4 of the 10 samples (\#1, 2, 6, and 7) received the same intelligibility rating by all 4 listeners. The range of ratings by the four listeners for one sample (\#5) was one point; for 4 samples (\#3,4,9, and 10), the range was 2 points; and for 1 sample (\#7), the range was 3 points (see Table 1). Among the articulation ratings, four of the samples received a rating range of one point (\#2, 8,9, and 10); and six of the samples received a rating range of 2 points ( $\# 1,3,4,5,6$, and 7 ), while none of the samples received the same rating by all 4 raters (Table 2 ). Two of the samples (\#5 and 6) received the same rating for rate by all 4 listeners (Table 3 ). One sample received a rating range of 1 point (\#2), while the range for four samples (\#1, 3, 9, and 10) was 2 points, and four other samples ( $\# 4,7$, and 8)) received a rating range of 3 points (Table 3 ). Ratings for resonance ranged 


\section{Table 1}

Range and Mean of Intelligibility Ratings Among All Four Listeners.

\begin{tabular}{ccccccccccc} 
& \multicolumn{10}{c}{ Speech Samples } \\
\cline { 2 - 9 } & 1 & 2 & 3 & 4 & 5 & 6 & 7 & 8 & 9 & 10 \\
\hline Rater A & 6 & 7 & 5 & 5 & 6 & 7 & 4 & 6 & 5 & 5 \\
Rater B & 6 & 7 & 7 & 6 & 7 & 7 & 6 & 6 & 5 & 6 \\
Rater C & 6 & 7 & 5 & 5 & 6 & 7 & 3 & 6 & 3 & 4 \\
Rater D & 6 & 7 & 5 & 7 & 7 & 7 & 5 & 6 & 7 & 5 \\
\hline $\begin{array}{l}\text { Range in } \\
\text { paints }\end{array}$ & 0 & 0 & 2 & 2 & 1 & 0 & 3 & 0 & 4 & 2 \\
\hline Mean & 6 & 7 & 5.5 & 5.75 & 6.5 & 7 & 4.5 & 6 & 5 & 5 \\
\hline
\end{tabular}

from 0 to 3 points. One sample (\#6) received the same rating for resonance from all 4 listeners (Table 4). The range of ratings for four samples (\#1, 2, 5, and 9) was 1 point; for three samples (\#3,4, and 10), the range was 2 points, and for two samples (\#7 and 8), the range was 3 points.

These interjudge and intrajudge reliability data demonstrate a variance among the four raters for all four rating scales. 
Table 2

Range and Mean of Articulation Ratings Among All Four Listeners.

\begin{tabular}{lllllllllll} 
& \multicolumn{110}{c}{ Speech Samples } \\
\cline { 2 - 10 } & 1 & 2 & 3 & 4 & 5 & 6 & 7 & 8 & 9 & 10 \\
\hline Rater A & 5 & 4 & 3 & 4 & 3 & 5 & 3 & 4 & 3 & 3 \\
Rater B & 5 & 5 & 5 & 4 & 5 & 5 & 4 & 5 & 4 & 4 \\
Rater C & 3 & 5 & 4 & 3 & 5 & 5 & 3 & 4 & 3 & 4 \\
Rater D & 5 & 5 & 3 & 5 & 5 & 3 & 2 & 5 & 3 & 3 \\
\hline $\begin{array}{l}\text { Range in } \\
\text { points }\end{array}$ & 2 & 1 & 2 & 2 & 2 & 2 & 2 & 1 & 1 & 1 \\
\hline \begin{tabular}{l} 
Mean \\
\hline
\end{tabular} & 4.5 & 4.75 & 3.75 & 3.75 & 4.5 & 4.5 & 3 & 4.5 & 3.25 & 3.5 \\
\hline
\end{tabular}


Table 3

Range and Mean of Rate Ratings Among All Four Listeners.

\begin{tabular}{lllllllllll} 
& \multicolumn{10}{c}{ Speech Samples } \\
\cline { 2 - 10 } & 1 & 2 & 3 & 4 & 5 & 6 & 7 & 8 & 9 & 10 \\
\hline Rater A & 5 & 5 & 5 & 5 & 5 & 5 & 4 & 5 & 5 & 5 \\
Rater B & 5 & 5 & 5 & 5 & 5 & 5 & 5 & 5 & 5 & 5 \\
& 3 & 4 & 3 & 2 & 5 & 5 & 2 & 2 & 3 & 3 \\
Rater C & 3 & & & & & & & & & \\
Rater D & 5 & 5 & 3 & 5 & 5 & 5 & 4 & 3 & 3 & 4 \\
\hline $\begin{array}{l}\text { Range in } \\
\text { points }\end{array}$ & 2 & 1 & 2 & 3 & 0 & 0 & 3 & 3 & 2 & 2 \\
\hline \begin{tabular}{l} 
Mean \\
\hline
\end{tabular} & 4.5 & 4.75 & 4.5 & 4.25 & 4 & 4 & 3.75 & 3.75 & 4 & 4.25 \\
\hline
\end{tabular}


Table 4

Range and Mean of Resonance Ratings Among All Four Listeners.

\begin{tabular}{lllllllllll} 
& \multicolumn{10}{c}{ Speech Samples } \\
\cline { 2 - 10 } & 1 & 2 & 3 & 4 & 5 & 6 & 7 & 8 & 9 & 10 \\
\hline Rater A & 4 & 4 & 5 & 5 & 5 & 5 & 5 & 5 & 4 & 4 \\
Rater B & 3 & 5 & 5 & 5 & 5 & 5 & 4 & 4 & 4 & 4 \\
& 3 & 5 & 4 & 3 & 4 & 5 & 2 & 2 & 3 & 2 \\
Rater C & 3 & & & & & & & & & \\
Rater D & 3 & 5 & 3 & 5 & 5 & 5 & 3 & 4 & 4 & 4 \\
\hline $\begin{array}{l}\text { Range in } \\
\text { points }\end{array}$ & 1 & 1 & 2 & 2 & 1 & 0 & 3 & 3 & 1 & 2 \\
\hline Mean & 3.25 & 4.5 & 4.25 & 4.5 & 4.75 & 5 & 3.5 & 3.75 & 3.75 & 3.5 \\
\hline
\end{tabular}




\section{Research Question 1}

The first research question to be answered was: do the speech features of articulation, rate, and resonance affect assigned intelligibility ratings of SLPs to Black English speaking preschoolers? In order to answer this question, each listener's intelligibility ratings were correlated with each of the independent variables (i.e., speech features) using Pearson $r$. Rater A demonstrated significant correlation between two variables and intelligibility: (a) articulation $(\underline{r}=.671 ; \underline{p}=.017)$, and (b) rate $(\underline{r}=.582, \underline{p}=.039)$. The correlation for resonance for this listener was insignificant $(\underline{r}=-.134, \underline{p}=.356)$. Rater $B$ also demonstrated a high correlation between two variables and intelligibility (a) articulation ( $\underline{r}=.701 ; \underline{p}=.012)$, and (b) resonance $(\underline{r}=.659 ; \underline{p}=.019)$. A value for rate could not be determined for Rater $B$ due to this listener's rating being the same for all speech samples. Rater $\mathrm{C}$ demonstrated a significant correlation between intelligibility and all three variables: (a) articulation $(\underline{r}=.705 ; \underline{p}=.011),(b)$ rate $(\underline{r}=.570, \underline{p}=.043)$, and (c) resonance $(\underline{r}=.675 ; \underline{p}=.016)$. Rater $\mathrm{D}$ demonstrated a significant correlation between intelligibility and two variables, (a) articulation $(\underline{r}=.525 ; \underline{p}=.06)$, and (b) resonance $(\underline{r}=.801$; $\underline{p}=.003)$. The correlation for rate for this listener was insignificant $(\underline{\mathrm{r}}=.172 ; \underline{\mathrm{p}}=.317)$.

In summary, correlations between all three speech variables and intelligibility was significant as rated by two of the 
raters. Significant correlations between two of the three variables resulted from the ratings of the other two raters, with resonance being an insignificant variable for Rater $A$ and rate being insignificant for Rater $D$. Rater C's variable of rate was not able to be computed due to a constant rating of 5 for speech samples. Thus, the perceived affect of articulation on intelligibility and intelligibility ratings were significantly correlated for all 4 raters, and the perceived affect of resonance and of rate were shown to be significantly correlated for 3 raters. These results show significant correlations between the assigned intelligibility rating and all three speech features investigated in this study.

\section{Second Research Question}

The second research question was: If the speech features assessed do affect assigned intelligibility ratings of SLPs to Black English speaking preschools, which of these speech features affect the assigned intelligibility ratings the most? To answer this question, a stepwise regression analysis was run for all 4 raters. This model provides the linear association between intelligibility and each assessed speech feature $(y=$ constant + coefficient $X$ variable). Raters $A, B$, and $C$ each demonstrated regression coefficients for articulation, noting this speech feature as a significant predictor of intelligibility. Rater A showed a regression value of $\underline{r}=.68$, and $\underline{r}^{2}=.46(\underline{p}<.05)$. Therefore, the 
stepwise model that includes articulation accounts for $46 \%$ of the variance in predicting intelligibility ratings. The regression coefficient for Rater B was $\underline{r}=.70$, with $\underline{r}^{2}=.49(\underline{p}<.05)$. The regression coefficient for Rater $\mathrm{C}$ was $\underline{\mathrm{r}}=.71$, with $\underline{\mathrm{r}}^{2}=.50(\mathrm{p}<$ $.05)$. Rater $\mathrm{D}$ was the only listener who did not demonstrate a significant correlation between articulation and intelligibility. For this listener, the regression analysis showed resonance to be the only significant predictor of intelligibility. The regression coefficient $\underline{r}=.80$, with $\underline{\mathrm{r}}^{2}=.64(\mathrm{p}<.05)$. Comparison of the listeners' linear regression coefficient values demonstrates articulation and intelligibility to be highly correlated; therefore, articulation was shown to be an accurate predictor of intelligibility, accounting for $46 \%$ to $50 \%$ of the variance for 3 of the 4 listeners.

\section{Discussion}

The interjudge reliability data showed differences among the listeners' ratings of all four variables examined in this study. Figure 5 demonstrates the range of intelligibility ratings as perceived by the 4 listeners, a difference of as much as three points on a 7-point scale among the four raters on a single speech sample. This difference represents a difference from less than essentially intelligible to less than sometimes intelligible, a difference that could clearly place a student between showing a need for service and not in need of service. Similarly, the 
Figure 5. Intelligibility Ratings of Speech Samples Assigned by 4 Raters.

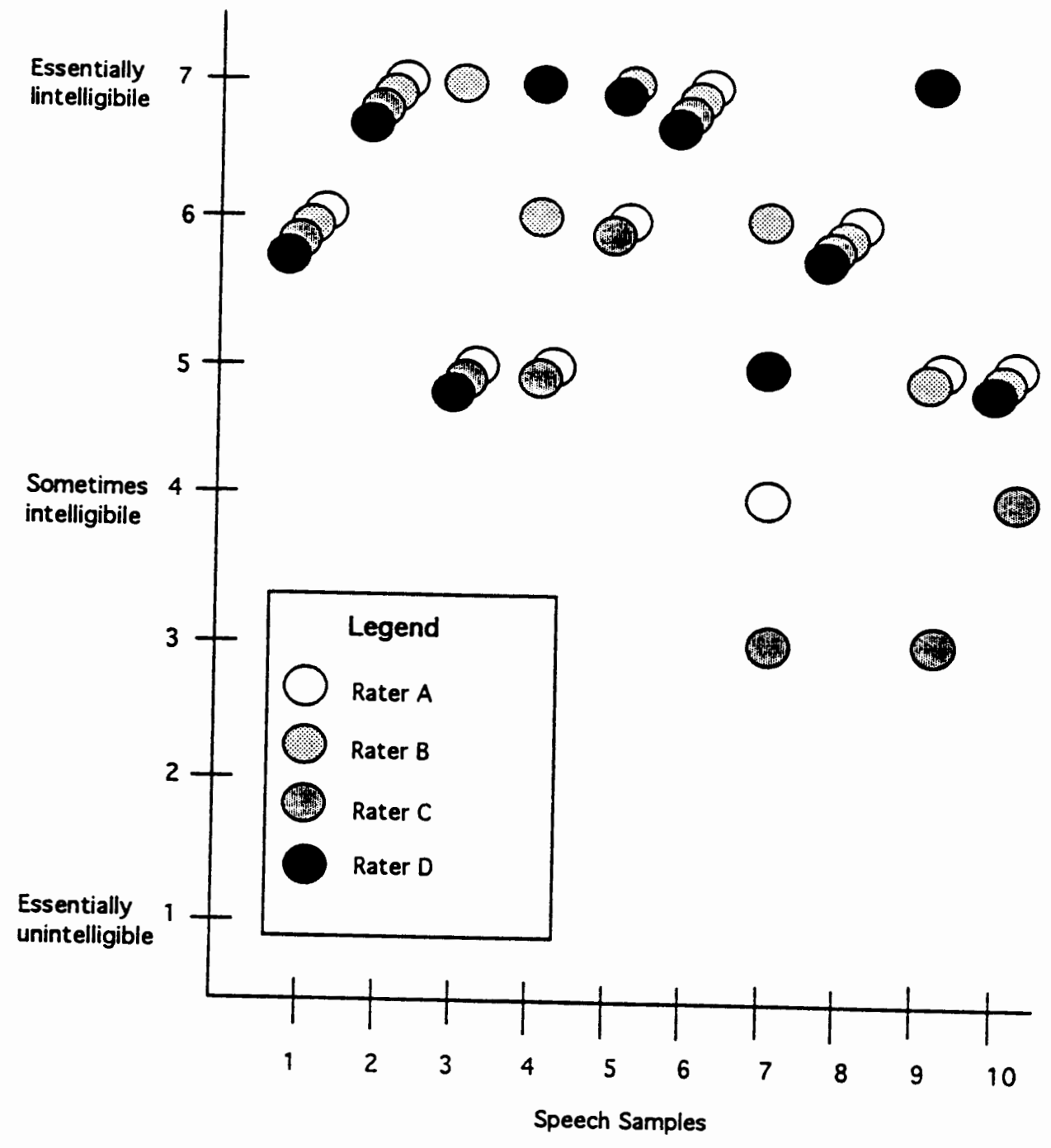


ratings for the perceived affect of these speech features ranged up to 3 points for resonance and rate, while articulation ranged up to two points between listeners. The perceived rating differences noted across all four areas that were rated by the listeners are not surprising. This variance can be a result of the subjective rating method used for this study. Rater's training and experience (both schooling and professional) varied, presumable affecting the listener's accuracy in rating these speech samples.

These data are a clear demonstration of the perceived differences listeners demonstrate with communication partners, especially when the communication partner is from linguistically diverse backgrounds (Eisenstein, 1982). The differences noted in this study may be evidence to support Finn's (1982) report that difficulties in the assessment of nonstandard English speaking students contribute to the overrepresentation of these students in special education classes.

Of particular interest is the identification of which listener perceived the greatest differences in severity. As mentioned in Chapter 3, the SLPs used for this study varied in years of experience with Black English speakers from less than 6 months to $3+$ years experience. Coincidentally, Rater $C$ was the listener with the least amount of experience (less than 6 months) with individuals who spoke Black English. Rater C, demonstrated a slight, but clinically significant difference in rating intelligibility 
for 2 of the 10 speech samples (Figure 5). Further examination of Rater C's overall ratings of rate and resonance demonstrated noticeable differences in ratings as compared to the ratings of the 3 more experienced raters (Raters A, B, and D). As demonstrated in Figure 6, assigned ratings for rate varied across listeners by as much as 3 points; in 7 of 10 samples, Rater $C$ assigned a rating that was at least 1 point more severe than the rest of the raters. Resonance ratings showed similar findings, with Rater $C$ rating 6 of the 10 speech samples 1 point more severe than the other three raters (Figure 7). No significant difference between Rater $\mathrm{C}$ and the more experienced raters, however, was noted for articulation (Figure 8). The difference in ratings among the listeners suggest an individual with less experienced with this group of speakers may perceive a more severe involvement in rate and resonance, over $50 \%$ of the time, as it affects a speaker's intelligibility than do the listeners' with more experience. 
FIGURE 6. Assigned Rate Ratings for all Speech Samples.

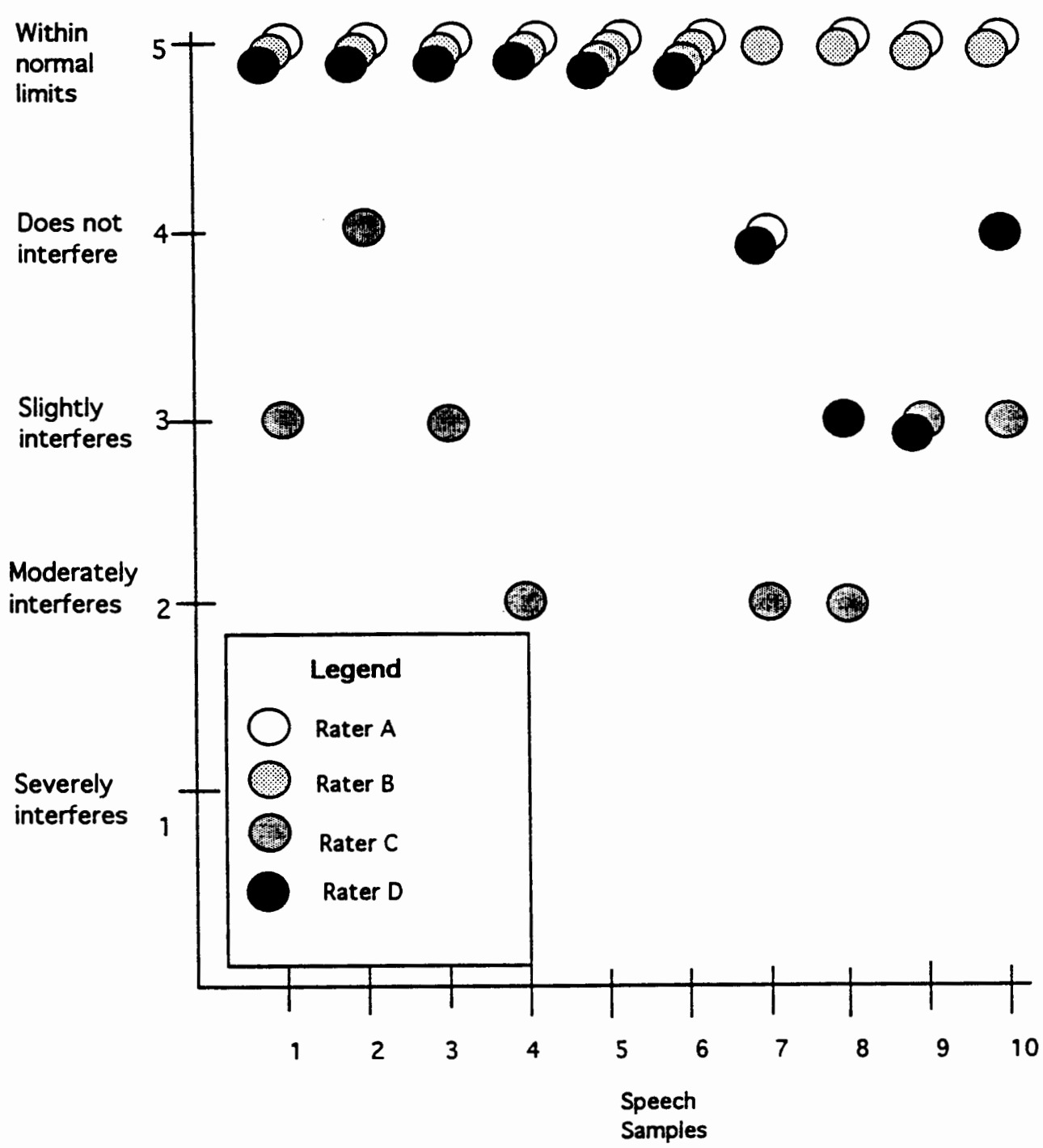


FIGURE 7. Assigned Resonance Ratings for all Speech Samples.

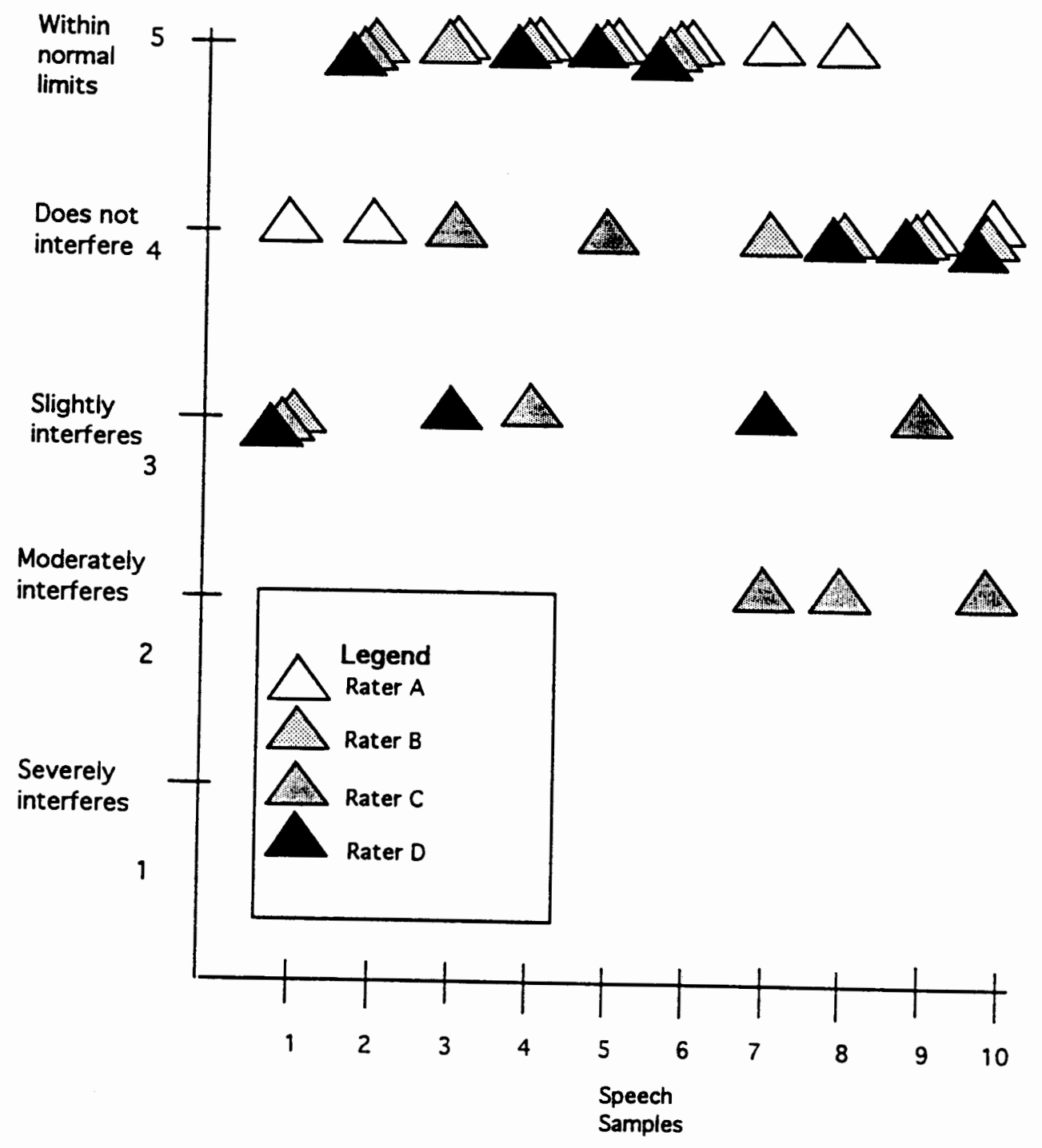


FIGURE 8. Assigned Ratings for Articulation for each Speech Samples.

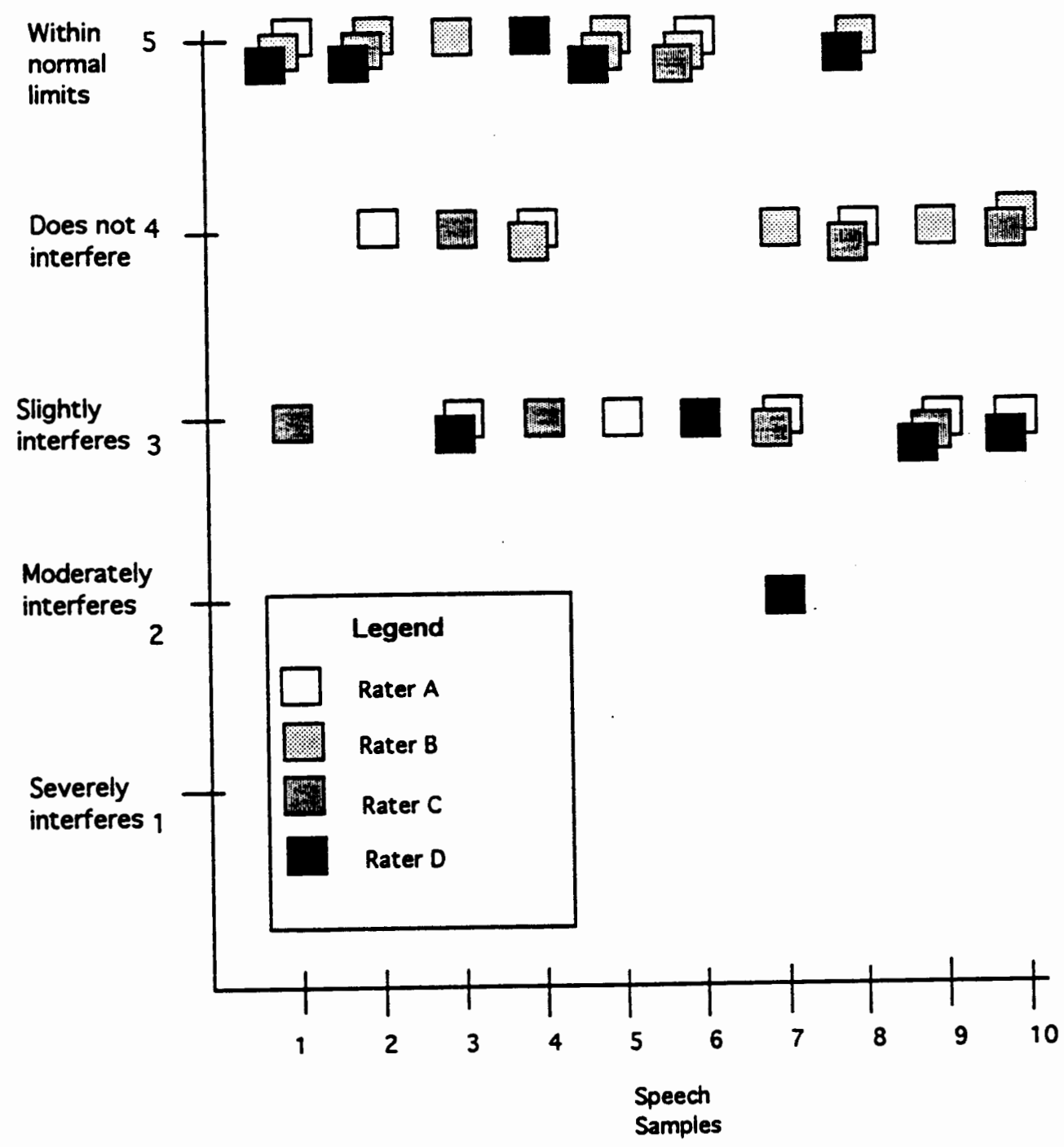


In this study, articulation was perceived by 3 of the 4 raters (Raters A, B, and C) to be the most important speech factor affecting intelligibly. In comparison with the literature, these data coincide with the research of several authors who suggest articulation variables affect intelligibility (Shriberg \& Kwiatkowski, 1982; Weiss, 1982) and more specifically contribute to the difficulty in understanding a speaker of a different dialect (Dale, 1976).

Remembering that all speech samples rated for this study had normally developing speech in relation to their own linguistic community (Soliday, 1993), the most experienced listener, Rater D, demonstrated the difference knowledge of the speaker's dialectical differences can make. Rater D's perception that resonance rather than articulation is the speech feature affecting intelligibility the most could very well be based on the increase awareness and experience of this listener with the linguistic differences of Black English speakers.

When comparing the linear associations of intelligibility and speech features for the least experienced listener, Rater C, and the most experienced listener, Rater D, the data demonstrate a perceived difference in how articulation affects intelligibility and therefore the listener's perceived judgment of the severity of the articulation difference. Rater $\mathrm{C}$ identified articulation as the only factor affecting intelligibility on all 4 speech samples identified as less than essentially intelligible (Figure 9). 
FIGURE 9. Relationship of Intelligibility and Assessed Speech

Features for Rater C.

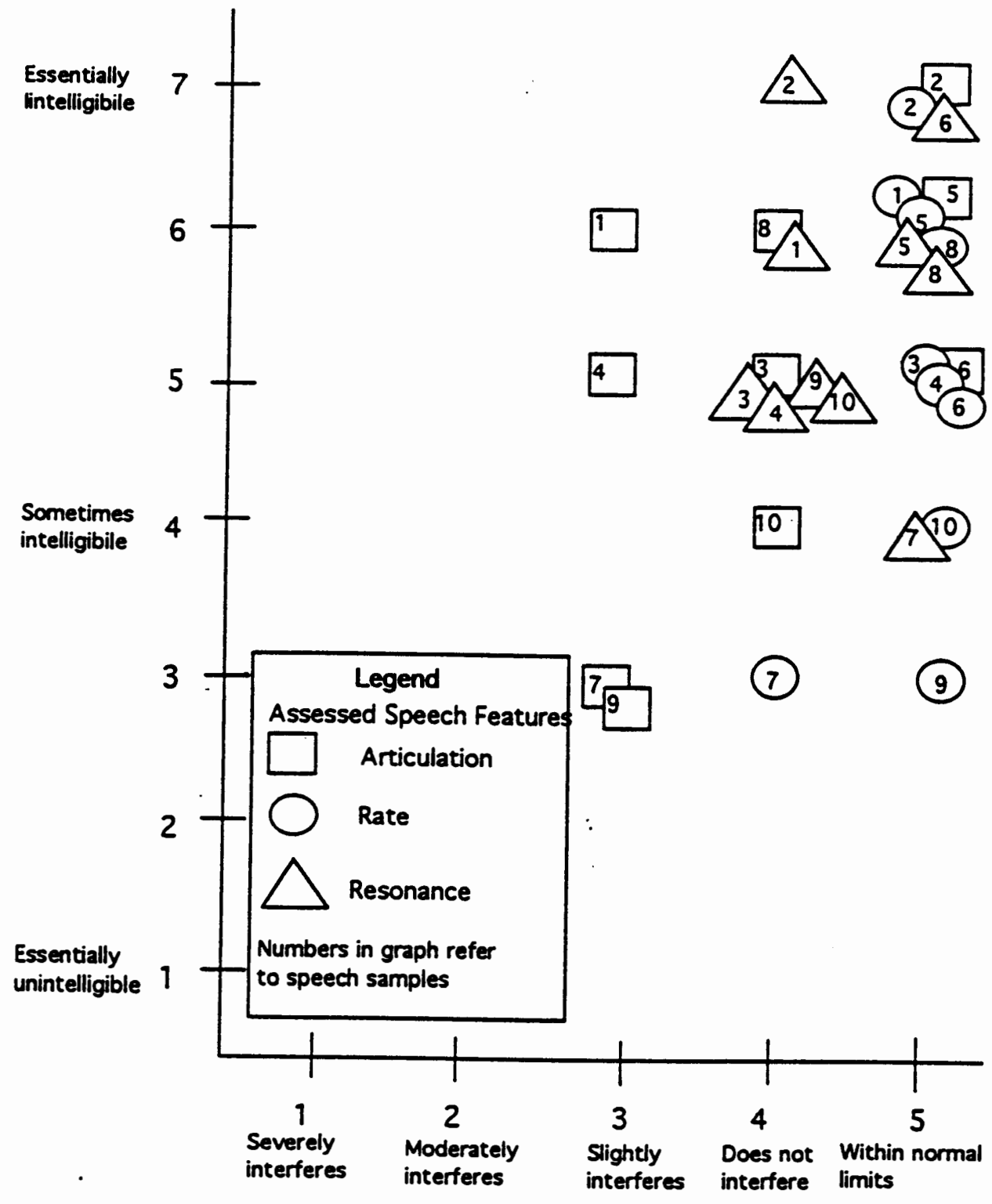


Among those samples rated less than essentially intelligible for Rater C, the ratings ranged from 6 (less than essentially intelligible) to 3 (less than sometimes intelligible). Although Rater D perceived a greater number of speech samples as less than essentially intelligible, all samples were rated better than sometimes intelligible ( $>5$ ). Articulation was perceived as the only factor having a rating of more than slightly interfering with intelligibility for one speech sample, and resonance was identified for every other sample identified by Rater D as $<7$ (essentially intelligible) and slightly interferes for intelligibility (Figure 10).

A conclusion can therefore be made that although articulation did demonstrate significant correlations for all 4 raters, a more linear association between resonance and intelligibility was identified by the most experienced listener, Rater D. This difference may be an example of Eisenstein's 1982 research findings, that the listener's ability to identify and categorize specific variables of dialect increases as proficiency develops. Although experience does not seem to demonstrate a significant difference for listeners with at least 1 year experience, the data from this study do show a noticeable difference in severity ratings for the listener with less than 6 months experience. And with literature still unavailable regarding most of the issues surrounding Black English, it is difficult to conclude how much experience is needed to make 
professional judgments accurately and ethically within the area of Black English as a standard English speaker.

FIGURE 10. Relationship of Intelligibility and Assessed

Speech Features for Rater D.

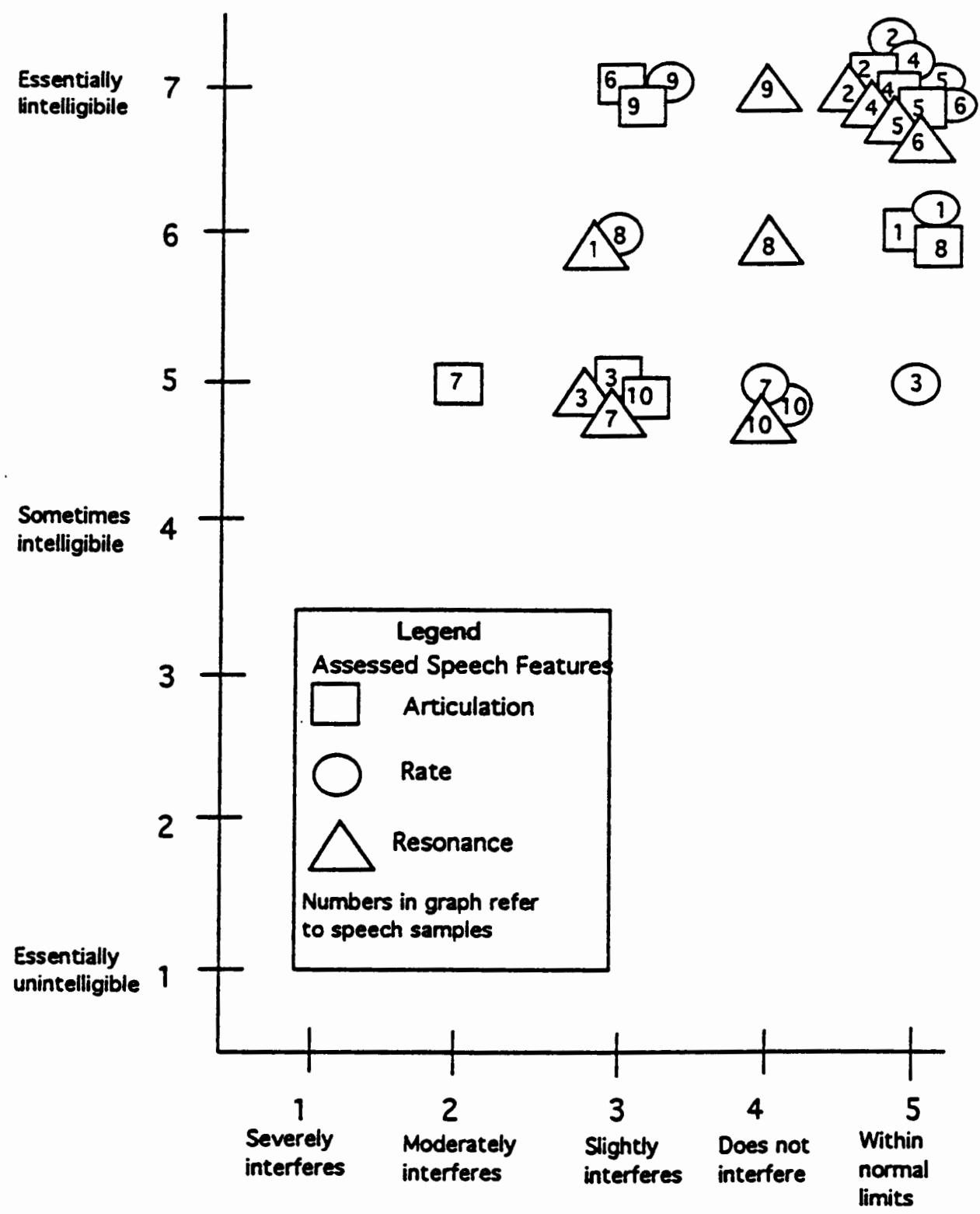




\section{CHAPTER V \\ SUMMARY AND IMPLICATIONS}

\section{Summary}

Linguistic diversification within our public schools has enriched and expanded our children's education. With this opportunity rises also the responsibility of the professionals within the education field to develop and maintain an understanding of the cultural and linguistic differences within the population we serve. Speech-language pathologists play a critical role in this understanding, as they are responsible for both the formal observation and identification of students needing speech and/or language services as well as providing staff training to enhance other professionals' understanding of the linguistic differences within their classrooms.

Understanding and recognizing normal cultural linguistic differences is the responsibility of the SLP. The focus of this study was to begin to understand the relationship of three speech features to intelligibility ratings of 10 preschool-aged Black English speakers. The speech samples from this group were previously evaluated for cognitive, phonological, and receptive language skills with all speakers demonstrating ageappropriate outcomes on these assessments.

Intelligibility ratings were assigned to Black English speech samples by 4 licensed SLPs with varying experience. The SLP 
listeners also rated the perceived effect of articulation, speaking rate, and resonance on intelligibility. The ratings of 3 of the 4 listeners demonstrated a strong association between intelligibility ratings of the speech samples and their ratings of perceived effect of articulation on intelligibility. Ratings of the 4 th listener, the listener with the most experience ( $>3$ years), demonstrated a strong association between intelligibility and resonance, with articulation demonstrating a lesser linear association with intelligibility. In reviewing the 4 listeners' ratings, Rater $\mathrm{C}$, the listener with the least amount of experience with Black English, tended to assign higher severity ratings for 3 of the 4 areas rated; intelligibility, rate and resonance.

In conclusion, results indicated that the speech features of articulation, rate, and resonance do affect the assigned intelligibility ratings of Standard English speaking SLPs to Black English speaking preschoolers, and that the majority of the SLP listeners rated articulation to be the speech feature associated most with intelligibility.

\section{Implications}

\section{Research}

The answers to the two questions posed in this study are critically incomplete. Considerable additional research is needed to better assess the relationship between intelligibility ratings and other factors potentially influencing intelligibility. The 
factors identified by (Weiss, 1992) could be the basis of such an investigation. Replications of this study using more Black English speech samples and speech samples from a variety of different geographic locations would help determine if the findings of this study are accurate. It would be interesting to investigate the influence of speech features when listeners have available to them their intelligibility ratings for the speakers, which was not the case for this study. Nonlinguistic factors affecting intelligibility (e.g., pragmatics, the listener's relationship with the speaker, the speaker's topic, physical characteristics of the speaker that are distracting, environmental distractions, the psychological state of the listener, and the native languages of the speaker and the listener) must also be explored to provide SLPs with the knowledge of how these factors may influence intelligibility of a speaker. Without this information, a SLP can not accurately and ethically assess and provide service to increase an individual's effective communication.

A better understanding of the role experience has in the professional understanding of linguistic differences must also be explored further to provide SLPs with a better understanding of the factors influencing their assessments of persons from diverse cultures. A study comparing Standard English speaking and Black English speaking SLP ratings of intelligibility of Black English speakers would be useful to further explore the role of experience. 
Also, a study which compared various measures of intelligibility of Black English speakers, for example, percentage of words understood in orthographically transcribed connected speech samples, estimates of percentage of words understood, and intelligibility ratings as done in this study would be of interest and may prove beneficial for use with further assessment tools intended and designed for this population.

Beyond the scope of intelligibility, research must begin to explore the development of all nonstandard English languages. This research would allow clinicians to diagnose speech and language disorders and delays versus linguistic differences of the linguistically diverse populations they serve. SLPs can not adequately and effectively provide the unbiased assessment and service mandated without this research and additional resources available to them.

\section{Clinical}

Based on the results of this study, SLPs are cautioned to be aware of their experience and understanding of the student population they serve. Increased awareness of linguistic diversity within their caseload is critical. Articulation clearly plays an part in intelligibility of all speakers; however, SLPs serving speakers of Black English must also be aware of the role dialectical differences play. Educational programs often provide "reading material" on this subject; however, a hands-on approach 
to listening and understanding the differences is critical. An effective approach for SLPs working with diverse populations is to interact with persons in these diverse linguistic communities of their clientele. Practicum experience with linguistically diverse students must be made available and mandated by educational programs to provide student's the experience necessary to serve this population ethically and professionally. For educational programs, as well as for professionals already in the field, ASHA (1985) has outlined recommended competency and strategies in providing assessment and remediation services to nonstandard English speaking populations (Appendixes $G$ and H). 


\section{References}

American Speech-Language-Hearing Association, (1985). Clinical management of Communicatively handicapped minority language populations. ASHA, 27, (6) 67-74.

Beukelman, D. R., \& Yorkston, K. M. (1979). The relationship between information transfer and speech intelligibility of dysarthric speakers. Journal of Communication Disorders, 12, 189-196.

Bloom, L., \& Lahey, M. 1978). Language development and language disorders. New York: Wiley.

Casteel, R. (1971). Grid for diagnosing intelligibility. Unpublished manuscript, Portland State University, Portland, OR.

Cole, L. (1983). Dialectal responses for Black English: Explanation of Black English rules. In E. O. Werner \& J. D. Kresheck (Eds.), Structured photographic expressive language test - II. 12-15. Sandwich, IL: Janelle Publications. Connolly, J. H. (1986). Intelligibility: A linguistic view. British Journal of Communication Disorders, 21, 371-376.

Dale, P. (1976). Language development. Structure and function (2nd ed.). Columbus, OH: Merrill Publishing.

Damico, J. S. (1991). Descriptive assessment of communicative ability in limited English proficient students. In E. V. Hamayan \& J. S. Damico (Eds.), Limiting bias in the 
assessment of bilingual students (pp. 157-218). Austin, TX: Pro Ed.

Dunn, L. M. (1968). Special education for the mentally retarded: Is much of it justified? Exceptional Children, 34, 5-21. Edwards, W. F. (1980). Two varieties of English in Detroit. In G. Smitherman (Ed.), Black English and the education of black children and youth (pp. 36-39). Proceedings of the national Invitational Symposium on the King decision, February 2-23, 1980. New Detroit.

Eisenstein, M. (1982). A study of social variation in adult second language acquisition. Language Learning, 32, 367-397.

Eisenstein, M., \& Verdi, G. (1985). The intelligibility of social dialects for working-class adult learners of English. Language Learning, 35 (2), 287-298.

Fayer, J. M., \& Krasinski, E. (1987). Native and nonnative judgments of intelligibility and irritation. Language Learning, 37, 313-326.

Finn, J. D. (1982). Patterns in special education placement as revealed by OCR surveys. In K. Heller, W. Holzman, \& S. Messick (Eds.), Placing children in special education: A strategy for equality (pp. 322-381). Washington, DC: National Academy Press.

Fudala, J. B., \& Reynolds, W. M. (1986). Arizona articulation proficiency scale (2nd ed.). Los Angeles: Western Psychological Services. 
Gordon-Brannan, M. (1993). Speech intelligibility assessment of young children with varying levels of phonological proficiency deficiency. Unpublished doctoral dissertation, Wichita State University, Wichita, KS.

Gordon-Brannan, M. (1994). Assessing intelligibility: Children's expressive phonologies. Topics in Language Disorders, 14, 17-25.

Guilford, J. P. (1954). Psychometric methods. New York: McGraw-Hill.

Hamayan, E. V., \& Damico, J. S. (1991) Limiting the bias in the assessment of bilingual students. Austin, TX: Pro-Ed.

Henrie, S. N. (1969). A study of verb phrases used by fiveyear-old non-standard Negro speaking children. Unpublished doctoral dissertation, University of California, Berkeley. In I. Stockman, A developmental study of Black English. (Tech. Rep. No. 143). Washington, D.C.: National Institute of Education. Hodson, B. W. (1986). The assessment of phonological processes- Revised. Austin, TX: Pro-Ed.

Ingram, D. (1981). Procedures for the phonological analysis of children's language. Baltimore: University Park Press.

Kent, R. D. (1992). Speech intelligibility and communicative competence in children. In A. P. Kaiser, \& D. B. Gray (Eds.), The social use of language intervention (pp.236267). Baltimore, MD: Brooks. 
Kovac, C. (1980). Children's acquisition of variable features. Unpublished doctoral dissertation, Georgetown University, Washington, D.C.. In I. Stockman, A developmental study of Black English. (Tech. Rep. No. 143). Washington, D.C.: National Institute of Education.

Labov, W. (1980). Recognizing Black English in the classroom. In J. W. Chambers (Ed.), Black English educational equity and the law 5672. Ann Arbor, MI: Karoma Publishers.

Macnamara, J. (1967). The bilingual's linguistic performance - a psychological overview. Journal of Social Issues, $\underline{23}, 58-77$.

Mercer, J. R. (1983). Issues in the diagnosis of language disorders in students whose primary language is not English. Topics in Language Disorders, $\underline{3}, 46-56$.

Metz, D. E., Schiavetti, N., \& Sitler, R. W. (1980). Toward an objective description of the dependent and independent variables associated with intelligibility assessments of hearingimpaired adults. In J. D. Subtelny (Ed.), Speech assessment and speech improvement for the hearing impaired (pp. 72-81). Washington, D. C.: The Alexander Gram Bell Association for the Deaf, Inc.

Monsen, R. B. (1981). A usable test of speech intelligibility of deaf talkers. American Annuals of the Deaf, 126, 845-852. 
Morris, S. R., Wilcox, K. A., \& Schooling, T. L. (1995). The preschool intelligibility measure (PSIM). American Journal of Speech-Language Pathology, 4, 22-28.

Nicolosi, L., Harryman, E., \& Kresheck, J. (1989).

Terminology of communication disorders ( $3 \mathrm{rd}$ ed.). Baltimore, MD: Williams \& Wilkins.

Office of Civil Rights (1980). Elementary and secondary school civil rights surveys. In E. V. Hamayan \& J. S. Damico (Eds.), Limiting the bias in the assessment of bilingual students (pp. 6-8) Austin, TX: Pro-Ed.

Olshtain, E., Shohamy, E., Kemp, J., \& Chatow, R. (1990). Factors predicting success in EFL among culturally different learners. Language Learning, 40, 23-29.

Ortiz, A. A., \& Maldonado-Colon, E. (1986). Reducing inappropriate referrals of language minority students of special education. In A. C. Willig \& H. F Greenberg (Eds.), Bilingualism and learning disabilities (pp. 37-52). New York: American Library Publishing Co.

Ortiz, A. A., \& Wilkinson, C. Y. (1987). Limited English proficient and English proficient Hispanic students with communication disorders: Characteristics at initial assessment and at reevaluation. Austin, TX: The University of Texas, Handicapped Minority Research Institute on Language Proficiency. 
Owens, R. E. (1988). Language development: An introduction (2nd ed.). Columbus OH: Merrill Publishing.

Patterson, J. L. (1994). A tutorial on sociolinguistics for speech-language pathologist: An appreciation of variation. NSSLHA Journal, 21, 14-30.

Reverton, W. W. (1978). The acquisition of four Black English morphological rules by Black preschool children. Unpublished doctoral dissertation, Ohio State University, Ohio. In I. Stockman, A developmental study of Black English. (Tech. Rep. No. 143). Washington, D.C.: National Institute of Education.

Rueda, R. (1987). Social and communicative aspects of language proficiency in low-achieving language minority students. In H. Trueba (Ed.), Success or failure? Learning and the language minority student (pp. 185-197). New York: Newbury House.

Schiavetti, N. (1984). Scaling procedures for quantification of speech, language, and hearing variables. In R. G. Daniloff (Ed.), Articulation assessment and treatment issues (pp. 237-253). San Diego, CA: College-Hill Press.

Schiavetti, N. (1992). Scaling procedures for the measurement of speech intelligibility. In R. D. Kent (Ed.), Intelligibility in speech disorders (pp. 11-34). Philadelphia: John Benjamins Publishing Company.

Shriberg, L. B, \& Kwiatkowski, J. (1982). Phonological 
disorders: A procedure for assessing severity of involvement. Journal of Speech and Hearing Disorders, 47, 357-377.

Soliday, S. E. (1993). Cultural bias in the assessment of phonological processes in conjunction with the APP-R. Unpublished thesis, Portland State University, Department of Speech Communication, Portland, OR.

Steffenson, M. (1974). The acquisition of Black English. Unpublished doctoral dissertation, University of Illinois, Champaign, Illinois. In I. Stockman, A developmental study of Black English. (Tech. Rep. No. 143). Washington, D.C.: National Institute of Education.

Stockman, I. (1982). A developmental study of Black English. (Tech. Rep. No. 143). Washington, D.C.: National Institute of Education.

Strokes, N. H. (1976). A cross-sectional study of the acquisition of negation structures in Black children. Unpublished doctoral dissertation, Georgetown University, Washington, D.C.. In I. Stockman, A developmental study of Black English. (Tech. Rep. No. 143). Washington, D.C.: National Institute of Education.

Taylor, O. (1987). Cross-cultural communication: An essential dimension of effective education (Guide No. 052). Washington, D.C.: American University, Mid-Atlantic Center for Race Equity.

Vaughn-Cooke, F. B. (1983). Improving language assessment in minority children. $\underline{\text { ASHA}}, \underline{25}$, Editorial. 
Weiss, C. E. (1982). Weiss intelligibility test. Tigard, OR: CC Publications.

Weiss, C., Gordon, M., \& Lillywhite, H. (1987). Clinical management of articulatory and phonological disorders (2nd ed.). Baltimore, MD: Williams \& Wilkins.

Wolfram, W., \& Fasold, R. (1974). The study of social dialects in American English. Newark, New Jersey: PrenticeHall.

Yavas, M., \& Lamprecht, R. (1988). Processes and intelligibility in disordered phonology. Clinical Linguistics \& Phonetics, 2 (4), 329-345.

Yorkston, K. M., \& Beukelman, D. R. (1978). A comparison of techniques for measuring intelligibility of dysarthric speech. Journal of Communication Disorders, 11, 499-512.

Yorkston, K. M., Beukelman, D. R., \& Bell, K. R., (1988). Clinical management of dysarthric speakers. Austin, TX: Pro-Ed. Young, M. A. (1969). Observer agreement: Cumulative effects of rating many samples. Journal of Speech and Hearing Research, 12, 135-143. 


\section{Appendix A \\ Explanation of Black English Rules}

(Cole, 1983)

Copula and auxiliary deletions. In BE all contracted forms of the copula and auxiliary forms is, are, have, will, and would are deleted.

The forms is and are may also be deleted as a whole while in the content of a (Wh) and yes-no question.

Multiple negatives. With the addition of each negative form within a sentence an increasing negative connotation is implied. In black English both the main verb phrase and infinitives can be negative. The following is an example of increasingly emphatic negative meaning:

I don't want a dress. (refusal)

I don't want no dress. (strong refusal)

I don't never want no dress. (stern refusal)

I don't never want no dress, no how. (underlying refusal)

Non-obligatory 3 rd person singular marker. The verb form in the third person singular verb form is regularized to conform to the other rules of person (e. g., I swim, you swim, he swim, we swim, they swim).

Non-obligatory possessive marker. The presence of a possessive marker is not required (e.g., Mark book for Mark's book).

Non-obligatory plural marker. The presence of a plural marker is not required (e.g., black cat for black cats).

Hypercorrection. A hypercorrection is the addition of plural, possessive or third person singular markers to forms that are previously 
marked or not so marked in standard English (e.g., childrens, I walks, we walks, that mines).

Pronominal apposition. A pronoun is used to restate the subject (e.g., The boy, he. ..).

Completive action auxiliary. Done is used to indicate an action completed in the past (e.g., He done went).

Alternative demonstrative. Them is used to indicate both subject and object and occurs where those is used in standard English (e.g., Them women for those women).

Consonant cluster reduction. The final consonant is deleted when two consonants occur in a cluster, both consonants have the same voicing and the final consonant is a stop.

The final ' $d$ can also be deleted by being absorbed into the following consonant when that consonant is a labial or velar, such as in "old boat" and "bad cat".

Distributive 'be'. Be is used to indicate a state or action intermittently distributed over time (e.g., He be bad).

Supplemental or pleonastic conjunctions. Contractions are joined with two conjunctions rather than one (e.g., She bought a dress and plus a pair of shoes).

At rule. At is used on the end of a where question (e.g., Where is my book at?).

Regularized reflexive pronouns. First, second, and third person reflexive pronouns are all formed with the possessive pronoun (e.g., hisself, herself, itself, and theirself). 
Remote past. Actions completed in the past that may continue in the present are indicated through he use of been (e.g., He been tired). Regularized concord. All persons and numbers are used with the concord form is (e.g., I is, you is, we is, etc.). In the past tense, the concord form was is used with all persons and numbers (e.g., I was, you was, we was, etc.). 
Appendix B

\section{Informed Consent}

I, agree to serve as a subject in the research project measuring understandability of African American preschoolers conducted by Britteny Asher, graduate student in the Speech \& Hearing Science Program at Portland State University.

I understand that this study will involve my listening to and subjectively rating eighteen audiotaped speech samples of Black English speaking preschoolers to determine my judgment of overall intelligibility of these samples as well as my professional opinion, as a licensed Speechlanguage pathologist, of the possible effect three predetermined speech features have on these ratings.

I understand that participation in this study will present no physical or psychological risks; however, it will require a maximum of 5 hours to listen and rate the audiotaped speech samples. My name will not be linked to any specific ratings which I assign during this study.

Britteny Asher has explained to me that the purpose of this study is to examine the intelligibility of African American preschoolers. I understand that I may not receive any direct benefit from participating in this study, but my participation may help to increase knowledge which would benefit others in the future.

Britteny Asher has offered to answer any questions I have about this study and what is expected of me in this study. I understand that I am 
free to withdraw from participation in this study at any time without jeopardizing my relationship with Portland State University.

I have read and understand the above information and agree to participate in this study.

Date: Signature:

If you have concerns or questions about this study, please contact the Chair of the Human Subjects Review Committee, Research and Sponsored Projects, 105 Nueberger Hall, Portland State University, 503/725-3417. 
Appendix C

Rating Scale for Intelligibility

ESSENTIALLY

UNINTELLIGIBLE

1

2

3
ESSENTIALLY

INTELLIGIBLE
4

5

6

7

SOMETIMES

INTELLIGIBLE 
Appendix D

Speech Features Affect on Intelligibility
Within Does not Slightly Moderately Severally normal interferes interferes interferes interferes limits

Articulation

5

4

3

2

1

Rate

5

4

3

2

1

Resonance

5

4

3

2

1 


\section{Appendix $\mathrm{E}$ \\ Description of Factors that Influences Intelligibility}

(Weiss, 1992)

Adventitious

Sounds:

Articulation:

Communicative

Disfluency:

Inflection:

Juncture:

Mean Length of

Utterance

Morphology:
The use of incidentals, nonessential, or abnormally placed or positioned sounds that compound speech perception, but different from communicative disfluency.

The adjustments and movements of the speech articulators used in producing oral communication.

Presence of "normal" hesitations, repetitions, broken or partial utterance, use of uh and um, and rephrasing.

Change in pitch or tone of voice.

A phonological boundary of a word, clause, or sentence.

Average number of words or syllables spoken each time a person speaks.

Form or structure of words, such as the formation of past *tenses or plurals. 
Morphophonemics: Elaborate derivational structure and rules of language, such as phonological changes that result when one morpheme is added to another; e.g., explain and explanatory. Stress change that sometimes included under morphophonemics should be considered separately under the category of stress.

Pauses: Unusually long or short, voiced or unvoiced pauses; or pauses used at inappropriate times.

Pitch: Appropriate vocal pitch for age, sex, and stature; and minimum pitch breaks.

Pronunciation: An accepted standard of pronouncing syllables and words; i.e., dialect.

Rate: Speed with which sound, syllables, or words are spoken.

Redundancy:

Characterized by unnecessary repetition, or a word that can have one or more forms; an utterance that refers to many different words making interpretation a process of guesswork, such as can be caused by the incorrect use of homonyms. 
Resonance:

Rhythm:

Semantics:

Stress:

Syntax:

Voice Quality:

Intensity:
Amplification of laryngeal sounds by coupling cavities of the mouth, nose, pharynx, and sinuses.

Uniform or patterned recurrence of a beat, accent, or melody in speech.

Correctness of the meaning of spoken words.

Emphasis in prominent loudness of syllable, word, or between compound words, such as blackboard and black board; or the difference between certain nouns and verbs, such as present and present.

Structures of the word order or arrangement in a phrase or sentence.

The phonatory characteristics of the vocal tract mechanism, such as vocal roughness or breathiness, but not to be confused with resonance.

Degree of audibility of the voice. The adequacy or inadequacy of loudness depends, in part, on the loudness level of the noise encompassing the speaking situation, although some voices 
are too loud or too soft regardless of the speaking environment. 
Appendix F

\section{Rater's Instructions}

You will be provided with four large labeled envelopes and a cassette tape containing 13 short speech samples, ranging from 2-4 minute, from children 3:6 to $4: 6$ years of age. The envelopes will be marked thus: Rating Scales for Intelligibility, Assessing Intelligibility Factors, Completed Intelligibility Rating, and Completed Assessment of Intelligibility Factors.

You will need to open the envelope labeled Rating Scales for Intelligibility for the first task. You will be rating the intelligibility of each child's speech on the rating sheet provided, using a 7-point rating scale, a rating of 1 indicates the child's speech essentially can not be understood, a rating of 4 indicates the child's speech is sometimes understandable, and a rating of 7 indicates the child's speech is essentially understandable. Please read the directions on the forms provided prior to listening to the taped samples.

Listen to the samples one at a time and circle the number on your Intelligibility Rating Scale which indicates your estimate of that child's intelligibility level. You must circle a number on the scale rather than spaces between the numbers. You will hear each sample only once for intelligibility rating so please listen carefully. You will be asked to rate all samples for intelligibility before moving to the next task. 
Once you have rated each sample for intelligibility you will listen to the tapes again, this time to assess how articulation, rate, and resonance affect intelligibility. Remove the forms located in the envelopes labeled Assessing Intelligibility Factors. Using a 5-point rating scale, 5 indicating the speech feature is within normal limits, 3 indicating the speech feature slightly interferes with intelligibility, and 1 indicating the speech feature severely interferes with intelligibility. You will rate all three of these speech features after you have listened to the speech sample for a second time. Again, you must circle a number on the scale rather than spaces between the numbers. Please read the directions on the forms provided prior to listening to the taped samples.

Thank you for your time, if you have any questions about what you are to do please contact me at 256-3390 before beginning. 


\section{Appendix G}

Competencies for Speech-Language Pathologists working with

Non-standard English speakers.

(From ASHA (1985), pp. 67-74.)

To provide assessment and remediation services in the minority language, it is recommended that speech-language pathologists or audiologist possess the following competencies:

LANGUAGE PROFICIENCY: Native or near native fluency in both the minority language and the English language.

NORMATIVE PROCESSES: Ability to describe the process of normal speech and language acquisition for both bilingual and monolingual individuals; and how those processes are manifested in oral and written language.

ASSESSMENT: Ability to administer and interpret formal and informal assessment procedures to distinguish between communication difference and communicative disorder.

INTERVENTION: Ability to apply intervention strategies for treatment of communication disorders in the minority language.

CULTURAL SENSITIVITY: Ability to recognize cultural factors which affect the delivery of speech-language pathology and audiology services to minority language speaking community. 
Appendix $\mathrm{H}$

Alternative Strategies for Use of Professional Personnel

(From ASHA (1985), pp. 67-74.)

It is recognized that not all speech-language pathologists and audiologist possess the recommended competencies to serve limited English proficient speakers. Following are some strategies for procuring speech-language pathologists who do meet the aforementioned competencies when there are none on staff.

\section{Establish Contacts}

Bilingual speech-language pathologist or audiologist can be hired by school districts and other clinical programs as consultants to evaluate and remediate minority language speakers on an as needed bases.

2. Establish Cooperative

A clinical cooperative can be developed to allow a group of school districts or clinical programs to hire an itinerant bilingual speech-language pathologist or audiologist whose primary responsibility is to serve a specific minority language population.

\section{Establish Networks}

Strong ties could be established between professional work setting and university programs that have bilingual speechlanguage pathologist or audiologist programs so that there can be an interchange of existing resources. Once such a liaison is established, it can facilitate recruitment of speech-language pathologists or audiologists who are competent to serve minority language populations after they graduate.

4. Establish CYF and Graduate Practicum Sites

Graduate students or recent graduates from bilingual communicative disorders programs, under direct supervision of bilingual speech-language pathologists or audiologists, could be used to assist personnel in schools and other clinical facilities in 
assessment and intervention of limited English-proficient individuals.

5. Establish Interdisciplinary Teams

A team approach can be implemented which includes the monolingual speech-language pathologist or audiologist and a bilingual professional equal (e.g., psychologist, special education teacher, etc.) who is knowledgeable of non-biased assessment procedures and language development of the particular minority language. 